This item was submitted to Loughborough's Research Repository by the author.

Items in Figshare are protected by copyright, with all rights reserved, unless otherwise indicated.

\title{
Carbody tilting - technologies and benefits
}

PLEASE CITE THE PUBLISHED VERSION

PUBLISHER

(C) Taylor \& Francis

VERSION

AM (Accepted Manuscript)

LICENCE

CC BY-NC-ND 4.0

REPOSITORY RECORD

Persson, Rickard, Roger M. Goodall, and Kimiaki Sasaki. 2019. "Carbody Tilting - Technologies and Benefits". figshare. https://hdl.handle.net/2134/6006. 
This item was submitted to Loughborough's Institutional Repository (https://dspace.lboro.ac.uk/) by the author and is made available under the following Creative Commons Licence conditions.

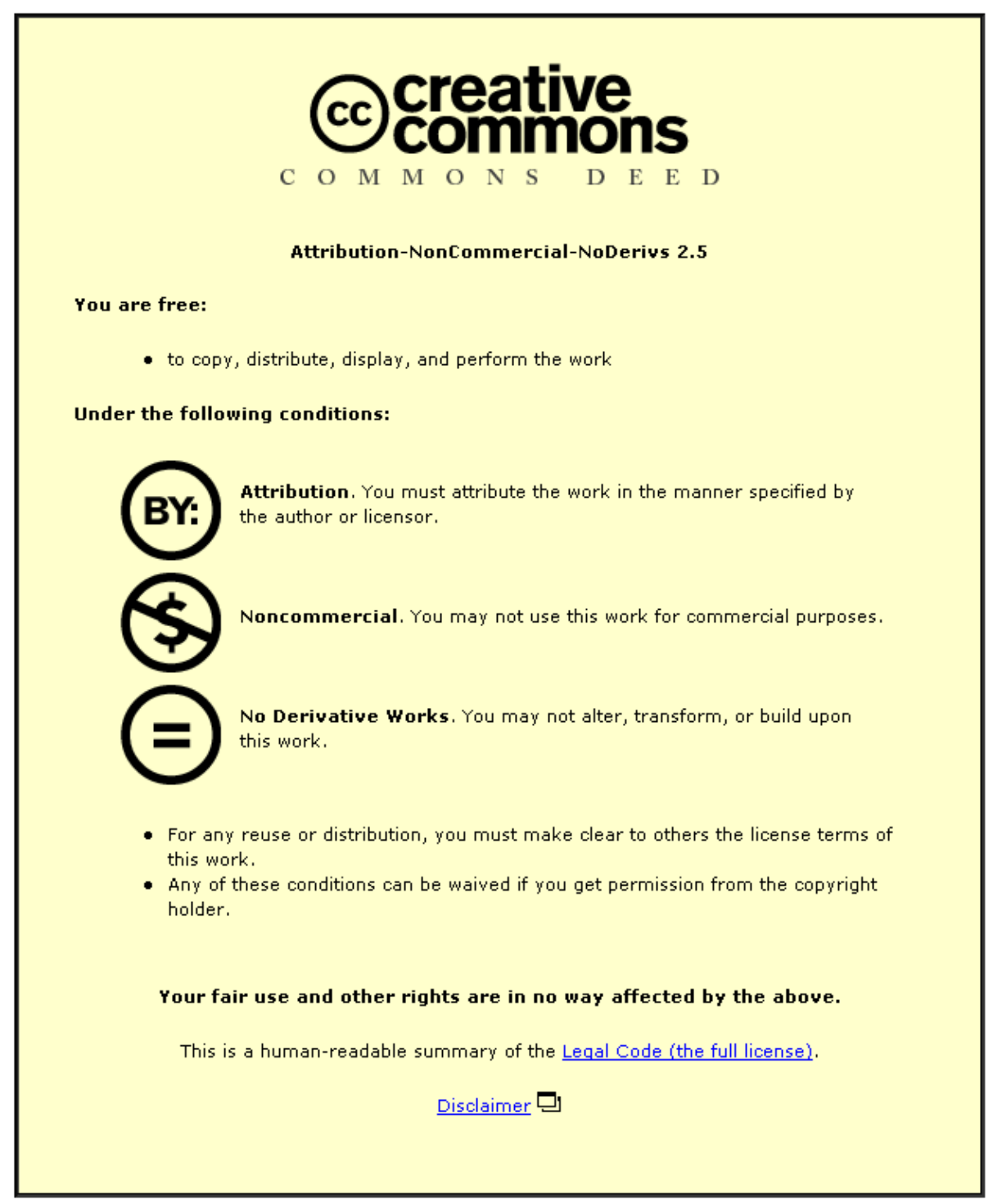

For the full text of this licence, please go to: http://creativecommons.org/licenses/by-nc-nd/2.5/ 


\title{
Carbody Tilting - technologies and benefits
}

\author{
Rickard Persson $^{\mathrm{a} *}$, Roger M. Goodall ${ }^{\mathrm{b}}$ and Kimiaki Sasaki ${ }^{\mathrm{c}}$ \\ a Department of Vehicle Dynamics, Bombardier Transportation, Östra Ringvägen2, 721 \\ 73 Västerås, Sweden; bepartment of Electronic and Electrical Engineering, \\ Loughborough University, Ashby Road, Loughborough, Leicestershire LE11 3TU, UK; \\ ${ }^{\mathrm{c}}$ Division of Vehicle Structure Technology, Railway Technical Research Institute, 2-8-38 \\ Hikari-cho Kokubunji-shi, Tokyo 185-8540, Japan \\ (Received 00 Month 200x; final version received 00 Month 200x)
}

\begin{abstract}
Carbody tilting is today a mature and inexpensive technology allowing higher speeds in curves and thus reduced travel time. The technology is accepted by many train operators. Today more than 5000 tilting vehicles, defined as tilting carbodies, have been produced world-wide by different suppliers. Tilting trains can be divided into naturally tilted trains and actively tilted trains. However, also natural tilting will often include actuation to ensure satisfactory dynamic performance. The mechanical solutions for tilting involving pendulums or rollers are well proven. They have also become compact enough to avoid passenger area intrusion. The proportion of the lateral acceleration compensated by tilt has decreased over the years. In the early days of tilting train development, it was often assumed that the compensation should be $100 \%$. Compensation of $50-70 \%$ are typically used in today's active tilting trains, while natural tilting ones still retain compensation close to $100 \%$. Recent developments in control have provided the market with more clever systems erasing the former problem with time delays. The result is beneficial for both ride comfort and low risk of motion sickness. As an example, running time simulations on the Swedish mainline Stockholm-Gothenburg have shown that the running time benefit for a tilting train vs. a non-tilting train, both with a top speed $275 \mathrm{~km} / \mathrm{h}$, is about $10 \%$.
\end{abstract}

Keywords: tilting trains; active tilt; natural tilt; tilting technology; tilting control; running time; ride comfort; motion sickness

\section{Introduction}

The International Union of Railways (UIC) [1,2] and Persson [3] have reported on tilting train technology, where tilting trains and known tilting technology are summarised. The present paper applies a world-wide perspective and includes the most recent research findings on control approaches giving a state-of-the-art paper on tilting train technology. The paper also shows the benefits of tilting trains, particularly expressed as running times. Further, the paper covers the human response to motions experienced on tilting trains.

\subsection{Concept and background}

A train and its passengers are subjected to lateral forces when the train passes horizontal curves. Carbody rolling inwards reduces the lateral acceleration felt by

*Corresponding author. Email: rickard.persson@se.transport.bombardier.com

ISSN: 0042-3114 print/ISSN 1744-5159 online

(C) 200x Taylor \& Francis

DOI: $10.1080 / 0042311 Y Y x x x x x x x x$

http://www.informaworld.com 
the passengers allowing the train to pass curves at enhanced speed with maintained ride comfort. Roll may be achieved by track cant or, when the track cant is insufficient, carbody tilt. Trains capable of tilting the bodies inwards in curves are often called tilting trains. Tilting trains can be divided into two groups: the naturally tilted trains and the actively tilted trains.

Natural tilt relies on physical laws with a tilt centre located well above the centre of gravity of the carbody. In a curve, under the influence of lateral acceleration, the lower part of the carbody then swings outwards. If there is no roll stiffness associated with the tilt centre then 'perfect' tilting action will arise where no lateral acceleration is experienced within the carbody, but in practice there will usually be a non-zero roll stiffness which means that there will be some residual lateral acceleration. Natural tilting will often include control and actuation to ensure satisfactory dynamic performance, in the present paper called active tilt support. Natural tilting is known as passive tilting in some countries. It should be noted that natural tilt has a negative impact on safety due to the lateral shift of the centre of gravity of the carbody.

Active tilt includes some form of mechanism by which the tilting of the carbody is created and relies upon control technology involving sensors and electronics and executed by an actuator, usually hydraulic or electric - without the actuation there is no significant tilt action. This form of tilt does not normally have an impact on safety of the train, as the centre of gravity does not essentially change its (lateral) position. Of course, the overturning moment is still increased as a consequence of the higher curving forces, but it is not exacerbated by the lateral centre of gravity shift mentioned in the previous paragraph and safety margins with active tilt only become unacceptable in high cross-winds - the issue of overturning is furthe discussed in Section 5.

The first considerations and experiments on reducing the centrifugal force felt by the passenger and thereby allowing higher speeds in curves date from the late 1930s [4,5]. In 1938, Pullman built an experimental pendulum coach for the Atchison, Topeka and Santa Fe Railway which became the first tilting coach in service [6]. The novel designs were based on natural tilt. The first large series of tilting trains were the Japanese class 381, which started to run between Nagoya and Nagano in 1973, and in 1980 Talgo Pendular trains using natural tilt technology were introduced into service in Spain [7].

Active technology was introduced in 1965 when Deutsche Bahn converted a diesel multiple unit series 624 for tilt. In 1972, a tilting version of series 624 , called series 634, was put into service on the line Cologne-Saarbrucken as the first actively tilted train in commercia service. One important development chain for actively tilting trains was the development of the Pendolino trains, which started in 1969 with a prototype tilting railcar, the Y0160. The prototype was developed in 1975 followed by Elettrotreni rapidi (ETR) 401, which became the first Pendolino in commercial service. Another important development chain started in 1973 when the Swedish State Railways (SJ) and ASEA signed a joint venture with the X15, which developed the tilt technology to the later X2000. In the early 1980s, there was a significant tilting train development in the UK as part of the Advanced Passenger Train programme [8], and a small number of these trains operated for a few years between London and Glasgow, but they never reached fleet operation and were discontinued before the end of the decade. The break-through for actively tilted trains came around 1990 with the introduction of large series commercial trains, such as the ETR450 in Italy and the X2000 in Sweden. At the same time, the Series 2000 trains were introduced in Japan, which were the first naturally tilted trains with active tilt support. In 2007, the Shinkansen Series N700 became the 
first high-speed tilting train in service.

Carbody tilting is today a mature and inexpensive technology allowing higher speeds in curves and thus reduced travel time. The technology is accepted by many train operators. Today more than 5000 tilting vehicles, defined as tilting carbodies, have been produced world-wide by different suppliers.

\subsection{The principle of tilting trains}

The basic principle of tilting trains is to roll the carbodies inwards during curve negotiation in order to reduce the lateral acceleration perceived by the passenger (Figure 1).

When a vehicle is running on a horizontal curve, there will be a horizontal acceleration, which is a function of speed $\mathrm{v}$ and curve radius $R$ (Equation (1))

$$
a_{h}=\frac{v^{2}}{R}
$$

The lateral acceleration in the track plane can be reduced compared with the horizontal acceleration by arranging a track cant $D$. The angle between the horizontal plane and the track plane, $\varphi_{t}$, is a function of the track cant and the distance between the two contact points of a wheelset $2 b_{0}$ (Equation (2))

$$
\varphi_{t}=\arcsin \left(\frac{D}{2 b_{0}}\right)
$$

The lateral acceleration, as perceived by the passenger, can be further reduced by arranging a carbody tilt angle $\varphi_{c}$ in relation to the track. The lateral acceleration in the carbody is denoted by $\ddot{y}$ (Equation (3)). The vertical acceleration, perpendicular to the carbody floor, is denoted by $\ddot{z}$ (Equation(4)).
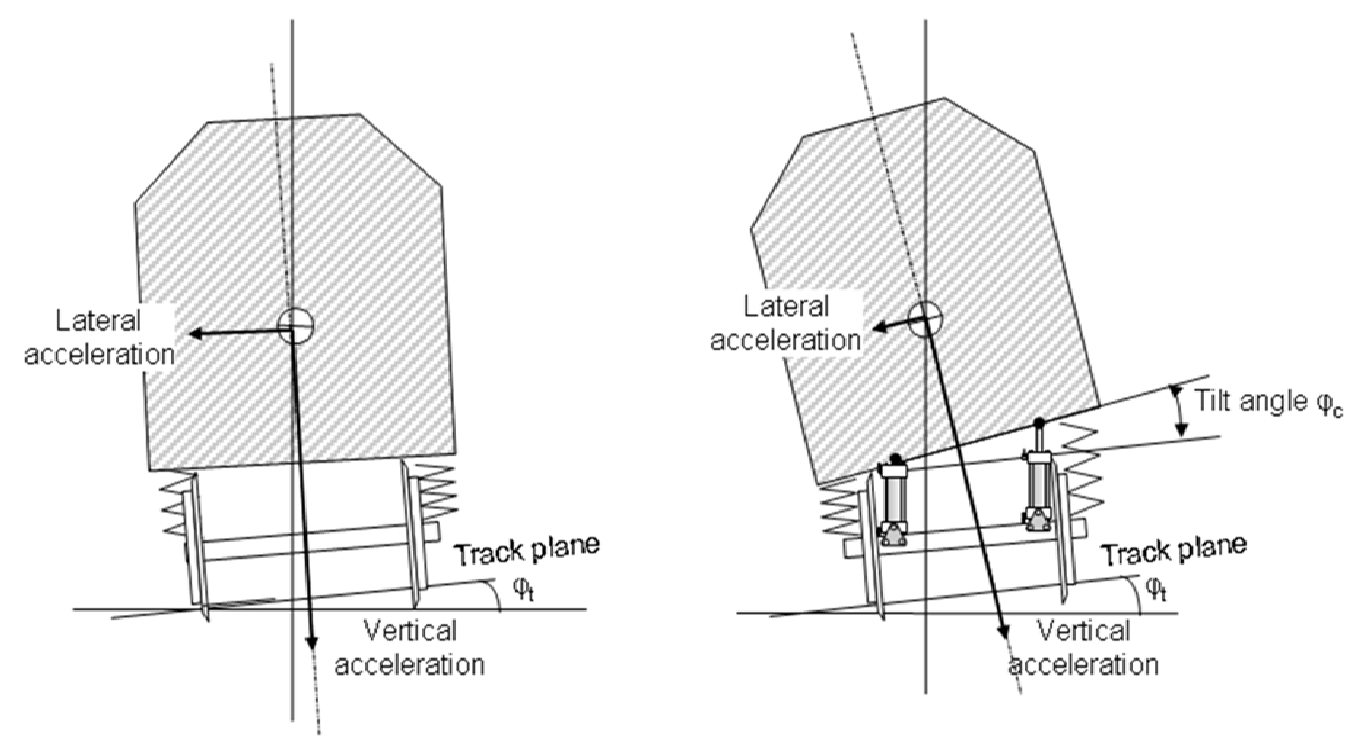

Figure 1. The basic concept of tilting trains. Despite the higher track plane acceleration for the tilting train (right), the lateral acceleration in the carbody is lower than for the non-tilting train (left) [3]. 
Table 1. Typical values for motion quantities on a horizontal curve.

\begin{tabular}{lccccc}
\hline $\begin{array}{l}\text { Speed } v \\
(\mathrm{~km} / \mathrm{h})\end{array}$ & $\begin{array}{c}\text { Radius } \\
R(\mathrm{~m})\end{array}$ & $\begin{array}{c}\text { Track } \\
\text { tilt angle } \\
\varphi_{\mathrm{t}}(\mathrm{deg})\end{array}$ & $\begin{array}{c}\text { Carbody } \\
\text { tilt angle } \\
\varphi_{\mathrm{c}}(\mathrm{deg})^{\mathrm{a}}\end{array}$ & $\begin{array}{c}\text { Lateral } \\
\text { acceleration } \\
\ddot{y}\left(\mathrm{~m} / \mathrm{s}^{2}\right)\end{array}$ & $\begin{array}{c}\text { Vertical } \\
\text { acceleration } \\
\ddot{z}\left(\mathrm{~m} / \mathrm{s}^{2}\right)^{\mathrm{b}}\end{array}$ \\
\hline 104 & 1000 & 0 & -1 & 1.0 & 0 \\
153 & 1000 & 5.7 & -1 & 1.0 & 0.15 \\
200 & 1000 & 5.7 & $6.5^{\mathrm{c}}$ & 1.0 & 0.44 \\
\hline
\end{tabular}

${ }^{\text {a }}$ Suspension deflections considered.

${ }^{\mathrm{b}}$ The vertical acceleration is here given as offset from $g$.

${ }^{\mathrm{c}}$ This tilt angle corresponds to an actively tilted train.

$$
\begin{aligned}
& \ddot{y}=\frac{v^{2}}{R} \cdot \cos \left(\varphi_{t}+\varphi_{c}\right)-g \cdot \sin \left(\varphi_{t}+\varphi_{c}\right) \\
& \ddot{z}=\frac{v^{2}}{R} \cdot \sin \left(\varphi_{t}+\varphi_{c}\right)-g \cdot \cos \left(\varphi_{t}+\varphi_{c}\right)
\end{aligned}
$$

A reduction of lateral acceleration by increased track cant and carbody tilt is correlated with a slightly increased vertical acceleration. Typical values for quasistatic lateral and vertical accelerations are shown in Table 1.

The last row in Table 1 represents what could be considered as typical values for an actively tilting train, including the key decision on what proportion of the lateral acceleration in the carbody is to be compensated. This proportion is named compensation factor and in the early days of tilting train development it was often assumed that the compensation should be $100 \%$, but in fact this both increases the required angle of tilt and has implications for ride comfort and motion sickness as discussed in Section 4. Compensation factors of 50-70\% are typically used in today's actively tilting trains, while natural tilting ones still retain compensation factors close to $100 \%$.

\section{Active tilting}

\subsection{Introduction to active tilting}

As observed in Section 1, active tilting has become the dominant tilting technology, at least for European railways. These systems require the following elements: a suitable mechanical arrangement to provide tilt, powered actuators to operate the system and sensors and controllers to provide effective operation. The historical development of trains that exploit active tilting has already been summarised, and so the aim of this section is to provide an overview of the mechanical, actuation, sensing and control issues, and then describe the state of the art of commercial/service trains that are currently in operation.

\subsection{Mechanical arrangements}

The requirement for active tilt is to provide rotation somewhere around the centre of gravity of the carbody, which both avoids the lateral shift of the centre of gravity and the consequent reduction in safety (mentioned in Section 1), and also minimises the impact upon the vehicle cross-section to meet loading gauge requirements. Excluding the pendulum arrangement, which is embodied in natural tilting, there are three mechanical arrangements which are possible to provide an active tilting system. These are tilt across, below and above the secondary suspension. 
The first approach, which can be called tilt across the secondary, is to achieve tilt directly by applying active control to the secondary roll suspension. One method that has been tried in both Europe and Japan is to apply differential control to the air springs, but if valves are used to inflate and deflate the air springs this causes a dramatic increase in air consumption from the compressor, significantly higher than is required for the braking system, for example, and generally has not found favour. However, one Japanese development has achieved it by transferring air between the long-stroke air springs using a hydraulically actuated pneumatic cylinder [9]. The alternative method of direct control of the roll suspension is by means of an active anti-roll bar (stabiliser), and this is applied in Bombardiers regional Talent trains [10]. This uses the traditional arrangement consisting of a transversely mounted torsion bar on the bogie with vertical links to the vehicle body, except that the links are replaced by hydraulic actuators, and thereby applies tilt via the torsion tube (Figure 2).

Tilt across secondary suspension is very much a minority solution, because most implementations use a tilting bolster to provide the tilt action. An important distinction is where this bolster is fitted compared with the secondary suspension, which leads to the second and third mechanical schemes. Both schemes use a mechanism of some kind in order to provide a rotation of the bolster, and typical schemes are shown in Figure 3.

With the tilting bolster above the secondary suspension, the increased curving forces need to be reacted by the secondary lateral suspension. This arrangement was employed in the early Italian Pendolino trains, and Figure 3 shows the scheme in which there is a coil spring secondary suspension with vertically mounted actuators providing the tilt action. However, since a stiffer lateral suspension is not consistent with providing a superior ride quality at the higher operating speed of a tilting train, in practice either an increased lateral suspension movement or some form of

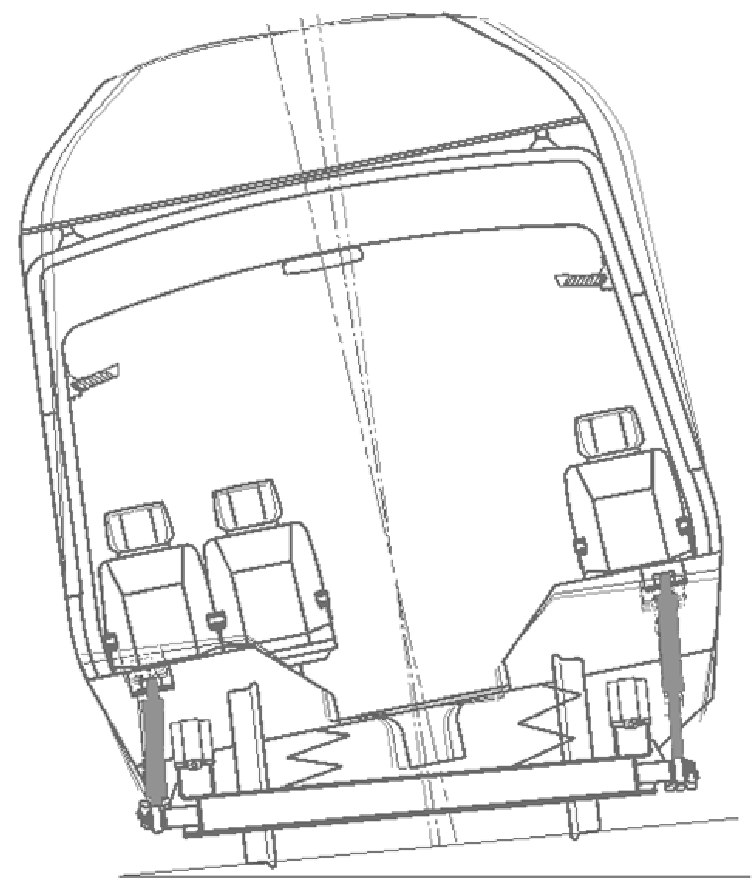

Figure 2. Basic scheme for active tilt applied across secondary suspension. 

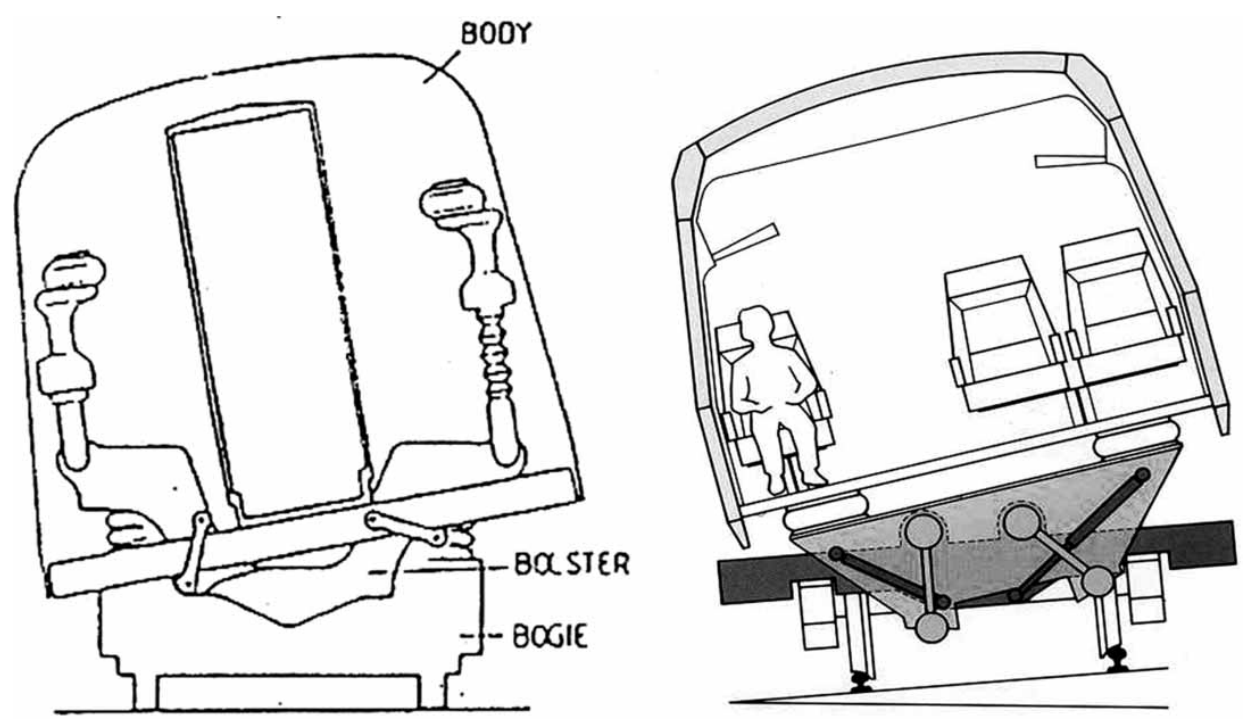

Figure 3. Tilt above (left) and below (right) secondary suspension.

active centring method is needed to avoid reaching the limits of travel. When the tilting bolster is below the secondary suspension, the base upon which the secondary suspension (usually air springs) is now-tilted, this avoids the increased curving forces on the lateral suspension. This is probably the most common of all schemes, the necessary rotation being achieved either using a pair of inclined swing links, or a circular roller beam, in both cases designed as explained to provide tilt about a 'virtual' centre a little above the floor of the carbody.

\subsection{Control and sensing}

A good tilt system is one which reacts quickly so that the applied tilt follows as closely as possible the progressive rise in cant deficiency through curve transitions, but at the same time reacts as little as possible on straight track otherwise it may degrade the lateral ride quality. Control and sensing strategies have progressively developed to meet this requirement, from rather simple early methods to more sophisticated approaches that characterise today's techniques.

\subsubsection{Control strategies}

Early ideas involved setting an accelerometer on the vehicle body to measure the lateral acceleration and provide a classical application of negative feedback in which the accelerometer signal is used to apply tilt in a direction that will bring it towards zero, yielding the 'nulling' controller shown in Figure 4. Implementation of the required value of the cant deficiency factor Kcd can be achieved with a modification of the basic nulling controller to give a partial tilt action by including a measure of the tilt angle in the controller, as shown by the dotted arrow in the figure. However, a difficulty was found with this scheme due to dynamic interaction within the lateral suspension between the roll and lateral modes - these modes are strongly coupled, and if the control loop bandwidth is low enough not to interfere with the lateral suspension, it is then too slow-acting on the curve transition.

This dynamic interaction problem can be avoided by setting the accelerometer on a nontilting part, in other words the bogie. This measures how much tilt is needed to reduce the lateral acceleration on the vehicle body to zero, so it is first multiplied by the cant deficiency factor $K_{c d}$. This 'tilt angle command signal' then 


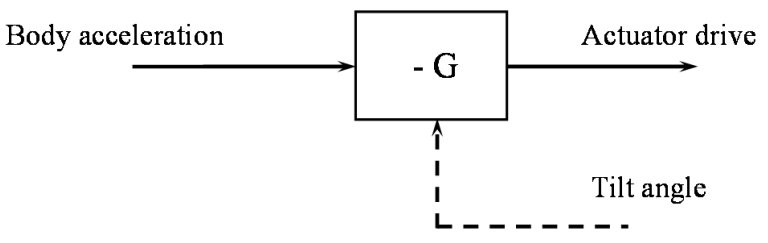

Figure 4. Nulling controller.

provides the input to a feedback loop which uses a measurement of the applied tilt angle (Figure 5). Because the accelerometer on the bogie is not only measuring the curving acceleration but also the pure lateral accelerations due to track irregularities (significantly larger when measured on the bogie), it is necessary to add a low-pass filter to reduce the acceleration signals caused by the track irregularities, otherwise there is too much tilt action on straight track resulting in a worse ride quality. Experience has shown that sufficient filtering introduces too much delay at the start of the curve: the full lateral curving acceleration is, therefore, felt for a short time, even though it reduces to the appropriate level once properly on the curve.

Figure 6 shows the next step: the signal from the vehicle in front is used to provide precedence, carefully designed so that the delay introduced by the filter compensates for the precedence time corresponding to a vehicle length. This scheme in effect is what most European tilting trains now use; sometimes roll and/or yaw gyros are used to improve the response, particularly to benefit the first vehicle in the train, and normally a single command signal is generated from the first vehicle and transmitted digitally with appropriate time delays down the train.

The signal from the bogie-mounted accelerometer is essentially being used to generate an estimate of the true cant deficiency of the track's design alignment, the difficulty being to exclude the effects of the track irregularities. An obvious development is to feed the vehicle controllers with signals from a database which defines the track, instead of from the accelerometer(s) as shown in Figure 6. However, both the position of each vehicle along the track and the curve data contained in the database need to be known accurately and reliably for this approach to work effectively, and the current focus is upon developing systems that bring together the two strategies (described further in Section 2.5).

A number of additional control approaches have been considered, including an 'inverse dynamics' technique to compensate for the suspension dynamics [11], which

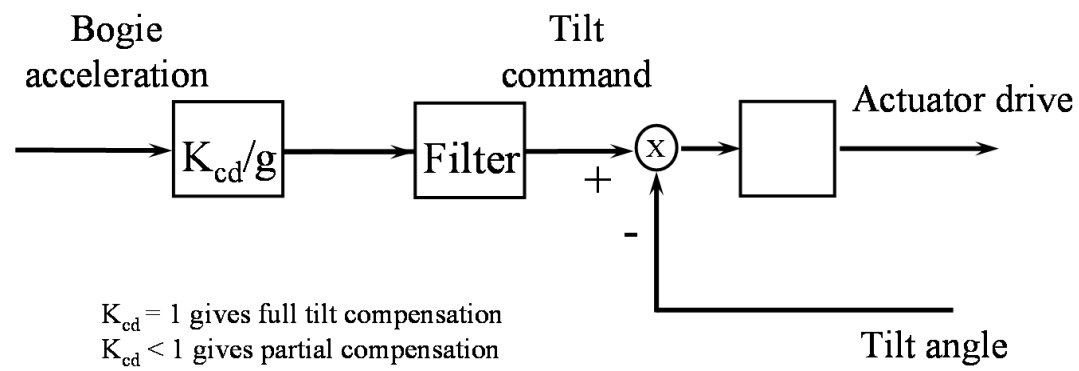

Figure 5. Command control strategy. 


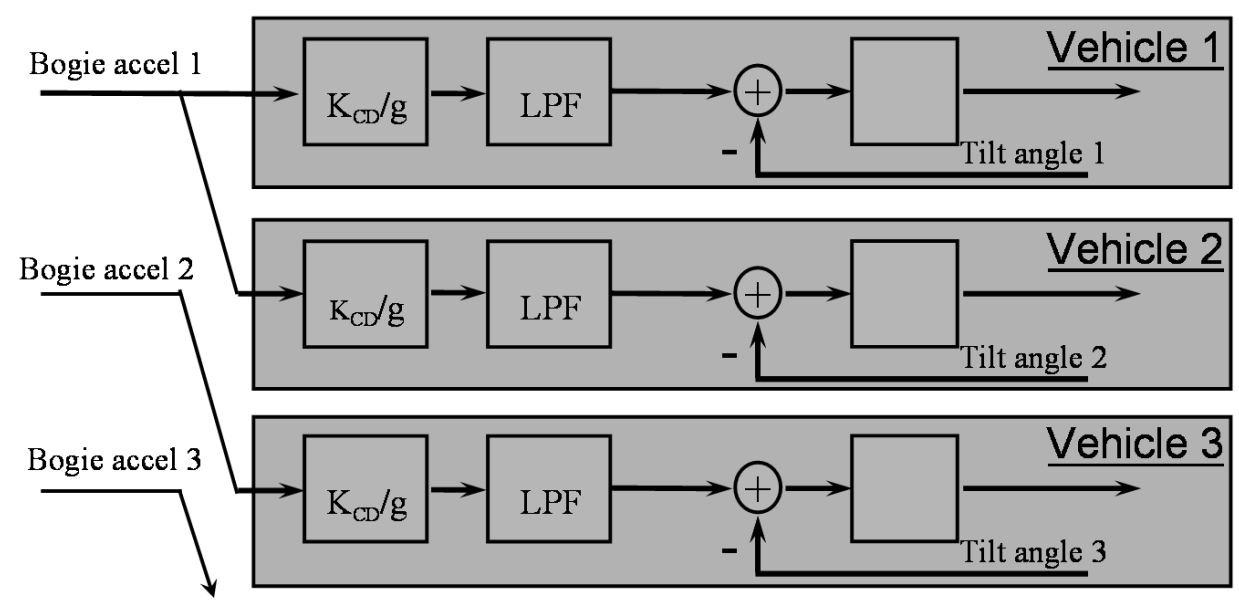

Figure 6. Precedence control strategy.

can be employed in conjunction with most of the above strategies, and various studies relating to achieving non-precedence strategies, i.e. based upon local vehicle measurements alone [12].

\subsubsection{Controller performance evaluation}

Qualitatively, a good tilt controller responds principally to the deterministic track inputs, and as much as possible ignores the random irregularities on straight track. In order to assess different tilt control strategies in an objective manner, it is necessary to define appropriate criteria and conditions and this sub-section explains a rigorous design approach that clarifies the issues that must be considered [13].

The straight track performance can be dealt with using a constraint criterion of degrading the lateral ride quality by no more than a specified margin compared with the non-tilting response, typically figures of $5-10 \%$ being appropriate, but the curve transition response has to be separated into two aspects.

First, the fundamental tilting response, measured, for example, by the PCT factors that are described in Section 4, should be as good as a passive vehicle at lower (non-tilting) speed, otherwise the passenger comfort will inevitably be diminished, no matter how effective the tilt control is. It is possible, therefore, to introduce the idea of 'ideal tilting' where the tilt action follows the specified tilt compensation perfectly, defined on the basis of the fundamental tilt system parameters $\mathrm{C}$ the operating speed (increase), maximum tilt angle and the cant deficiency compensation factor. This combination of parameters can be optimised for deterministic inputs in order to choose a basic operating condition, and defines the 'perfect' transition responses - Figure 7 shows typically how these might appear for both non-tilting and tilting situations with no track irregularities.

Secondly, it is necessary to quantify the additional dynamic effects that are caused by the suspension/controller dynamics as the transitions to and from the curves are encountered, which can be quantified as the deviations from the 'ideal' response. These deviations relate to both the lateral acceleration and roll velocity, although the former is likely to be the main consideration. The performance will depend upon the choice of sensors, the basic strategy and the detailed characteristics of the controller, the aim being for these deviations to be minimised: it is difficult to define their acceptable size, although the values derived for a normal passive suspension can be used as a guide. 

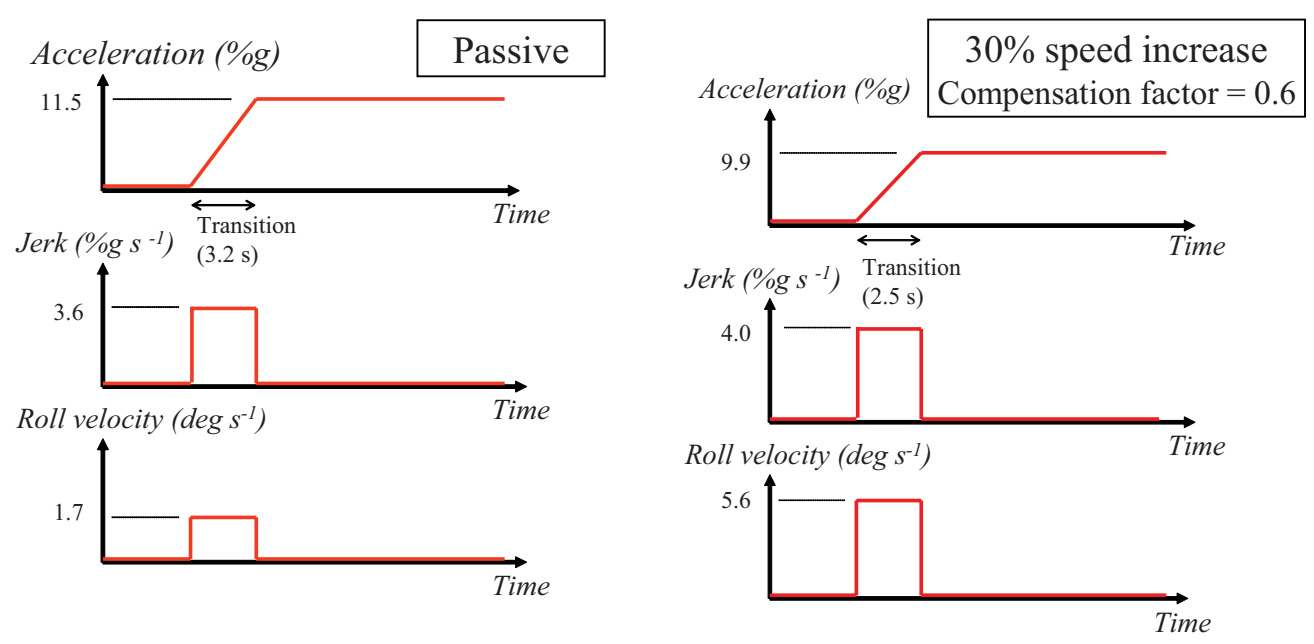

Figure 7. 'Ideal' non-tilting and tilting transition responses (6. cant deficiency, passive roll of $1^{\circ}$ ).

\subsection{Actuator technology}

Actuation systems in general include a power supply, some form of control amplifier and the actuator itself. The nature of these basic components depends entirely upon the chosen technology and the systems employed to provide tilt action have seen significant development since the early days of tilt. As mentioned in Section 2.1, some early systems were based upon controlling the air springs (i.e. intrinsically pneumatic actuation), but it was more normal to use servo-hydraulic actuator systems because these tended to be the natural choice for mechanically oriented railway engineers. Such hydraulic systems have a hydraulic power supply comprising an electric motor driving a pump giving fixed pressure, the flow from which is regulated by servo-hydraulic valves supplying hydraulic cylinders fitted between the bogie and tilting bolster. Experiments with electro-mechanical actuators in the UK in the late 1970s [14], in Switzerland in the 1980s [15] and in Germany in the 1990s [16] paved the way for a significant move away from the hydraulics. These have a DC-supply derived form the train's auxiliary electrical system, high-efficiency solid-state power amplifiers feeding electric motors that drive screws fitted with high-efficiency ball or roller nuts to convert rotary to linear motion. Figure 8 shows a typical electro-mechanical tilt actuator. They are less compact than hydraulic actuators at the point of application, but overall they provide significant system benefits and they are now employed in many of new European tilting trains, although Japanese tilting technology has tended to use pneumatic actuators. A hybrid technology is known as electro-hydraulic actuation, in which an electric motor driving a fixed-displacement pump is used with a sealed hydraulic circuit connected to normal hydraulic cylinders - control is via the power amplifiers that feed the motors, and there is no need for a separate hydraulic power supply.

\subsection{State of the art}

Whereas in Japan the focus has been upon natural tilting trains, the development of which is described in Section 3, all major European manufacturers now offer trains based upon mature and effective active tilt. This sub-section summarises the major developments that have taken place to provide a combined overview of the current state of the art. 


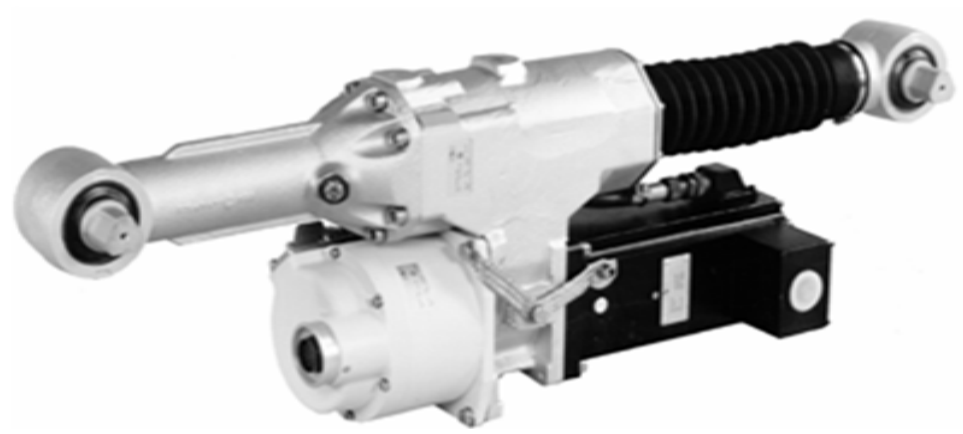

Figure 8. Electro-mechanical tilt actuator [17].

The early Pendolino trains designed by Fiat in Italy have evolved progressively: they still retain the original tilt-above-secondary swing link scheme, but the newest ETR610 trains have a much more compact mechanical arrangement and also use electro-hydraulic actuation (Figure 9, left hand diagram). The Alstom Pendolino trains take some of their technological heritage from Fiat but have introduced tiltbelow-secondary using a circular roller beam for the bolster instead of the swing links (Figure 9, centre) with electro-mechanical actuators [18], the latter being derived from developments in Switzerland by SIG prior to its acquisition by Fiat and subsequent merger into Alstom. This train has a number of tilt-related innovations, including the use of a single central air spring instead of the normal two per bogie, and an electrically driven anti-tilt mechanism for the pantograph. The Swedish X2000 train (Figure 9, right) has operated successfully in Sweden and elsewhere, with tilt-below-secondary using swing links and servo-hydraulic actuators. This is a similar mechanical scheme to that used by Bombardier in its early tilting LRC trains and the newer Acela Express for the US NE corridor. The same basic arrangement has also been further developed for the company's Super Voyager trains in the UK.

The significant innovation in terms of control and sensing is the enhancement arising from track database information. An example is Alstom's Tiltronix ${ }^{\circledR}$ system (Figure 10) which illustrates the sophisticated nature of modern tilt controllers utilising lateral accelerometer, roll and yawgyros, but also has the capability to synchronise the train's position with a database using its sensor signals and give
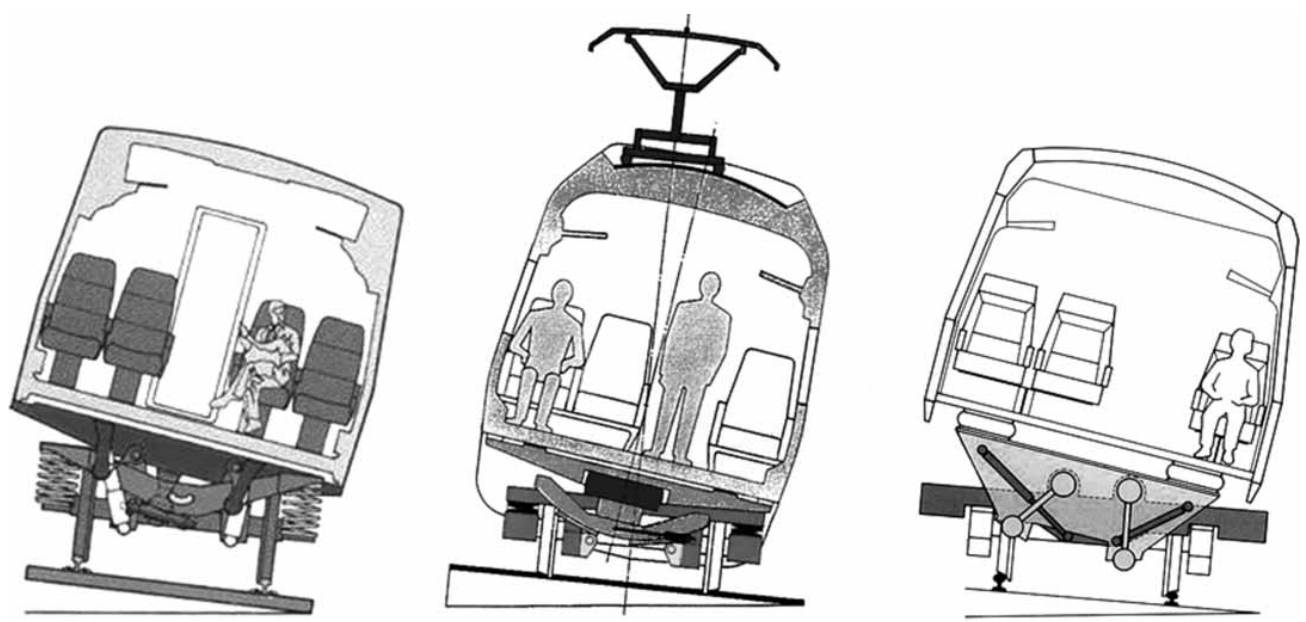

Figure 9. Modern active tilting trains: ETR610, Alstom Pendolino, Bombardier X2000. 


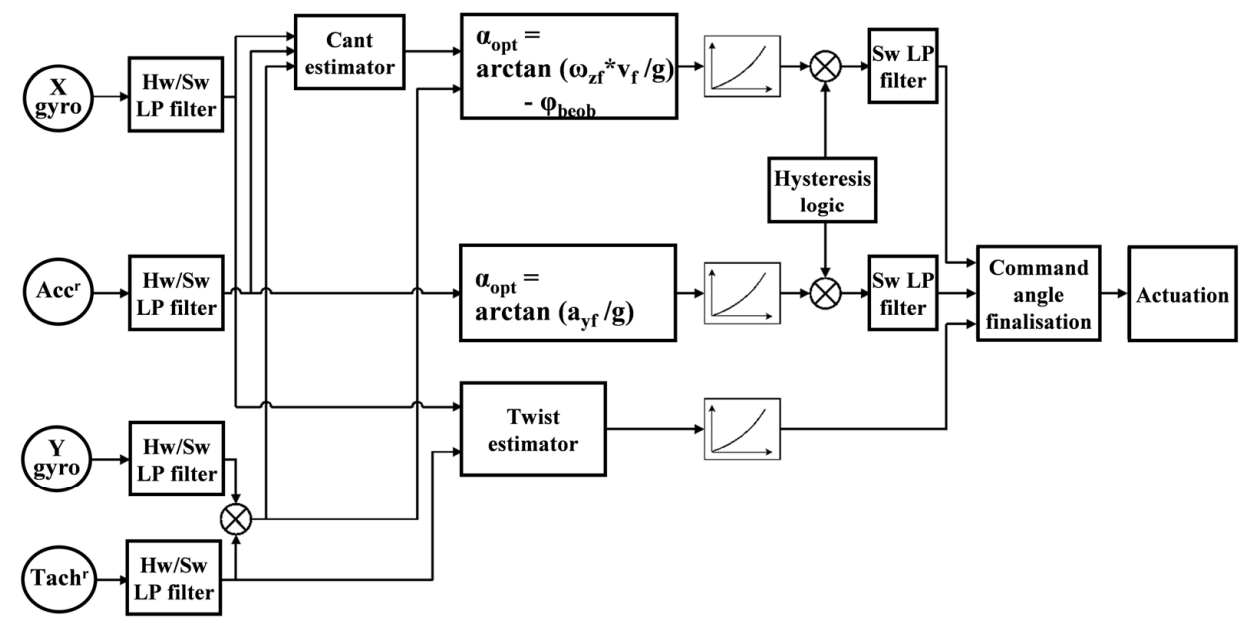

Figure 10. Modern active tilting controller

improved transition performance by means of knowledge of the curve ahead [19]. A similar 'data fusion' approach has also been developed by Railway Technical Research Institute (RTRI) in Japan although this uses a Global Positioning System (GPS), curvature signals from a yaw gyro and tachometer signals.

\subsection{Summary}

The review provided by this section has revealed the wide variety of technological options that exist for active tilting, a variety that is reflected in trains that are currently operating in service. It is not obvious that any particular solution has major advantages over another, or is emerging as a 'winner'; indeed, the fact that there are commercial opportunities for all such technology options underpins the robustness of the basic concept of active tilting as a key railway technology.

\section{Natural tilting}

\subsection{Introduction to natural tilting}

Natural tilting, or passive tilting, tilts the carbody by the centrifugal force acting on the carbody. In this system, the tilting centre is set higher than the carbody centre of gravity as shown in Figure 11 (left). When the train runs in curve sections, the lateral acceleration acts on the carbody and tilts the carbody. The lateral acceleration through tilting balances the track plane acceleration. Thus, the lateral acceleration of the carbody floor is cancelled. This motion resembles the behaviour of a pendulum; tilting trains are sometimes called pendulum trains. In this system, it is required that the effective carbody centre of gravity including the effect of secondary suspension is always lower than the centre of tilting. The opposite relation between centre of gravity and tilt centre would result in inversed tilting. If flexibility, like the secondary suspension, is put between the tilting device and carbody, as shown in Figure 11 (right), the mass centre of carbody receives a lateral displacement due to the lateral acceleration, which will reduce the tilt angle. This behaviour depends upon the tilting resistance of the tilting device and the lateral flexibility. In addition, it appears as the height the carbody centre of gravity is higher than it is. Thus the tilting centre of natural tilting cannot be as low as for active tilting. 


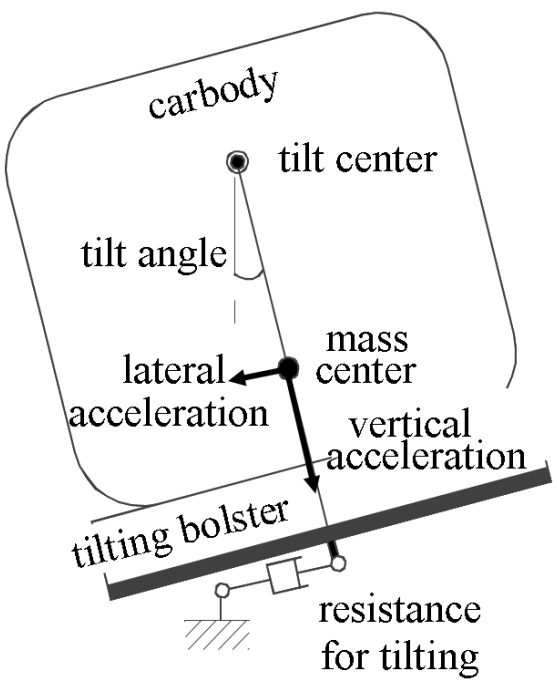

Without secondary suspension

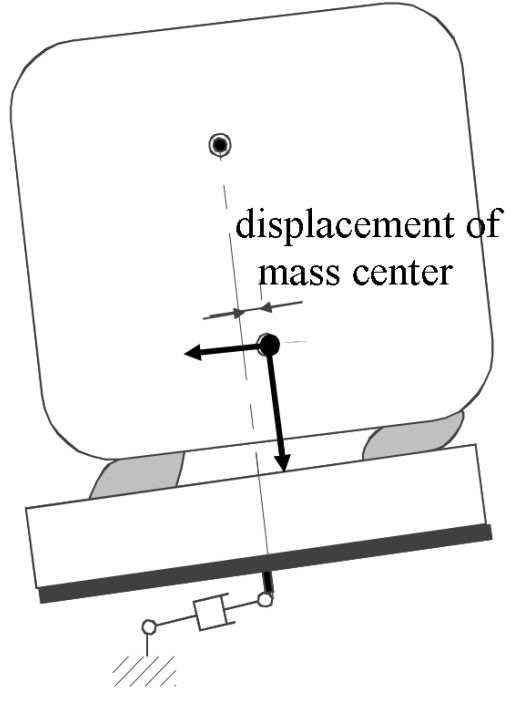

With secondary suspension

Figure 11. Mechanism of natural tilting

The merits of natural tilting are as follows:

(1) The control systems are very simple.

(2) It is possible to expect a failsafe system. Inversed tilting caused by curve detection error or controller failure does not occur. Operation stability can be assured even in failed condition as it is unnecessary to reduce the operating speed for those situations.

(3) A low-cost system may be expected.

The demerits of natural tilting are as follows:

(1) Carbody moment of inertia will delay tilt motion. Thus, a low-frequency lateral acceleration, caused by unbalance between track plane acceleration and the compensation by tilting, will appear in transition curves. This low-frequency lateral acceleration may cause motion sickness to sensitive passengers. Therefore, this system is not suitable for lines with many short transition curves.

(2) In the viewpoint of displacement of the carbody centre of gravity, it is advantageous to reduce the height difference between the carbody centre of gravity and the tilting centre. But as mentioned, the height of tilting centre should have enough margins to the carbody centre of gravity. Therefore, natural tilting trains have a lateral movement of the carbody mass centre, which increases the risk of over-turning.

\subsection{Mechanical arrangements}

This section shows typical mechanisms of natural tilting being used in commercial trains; swing bolster with circular guide (Figure 12) and high position air spring (Figure 13). The former is used in Japanese tilting trains, and the latter in the Talgo train of RENFE (Spain) [20]. 


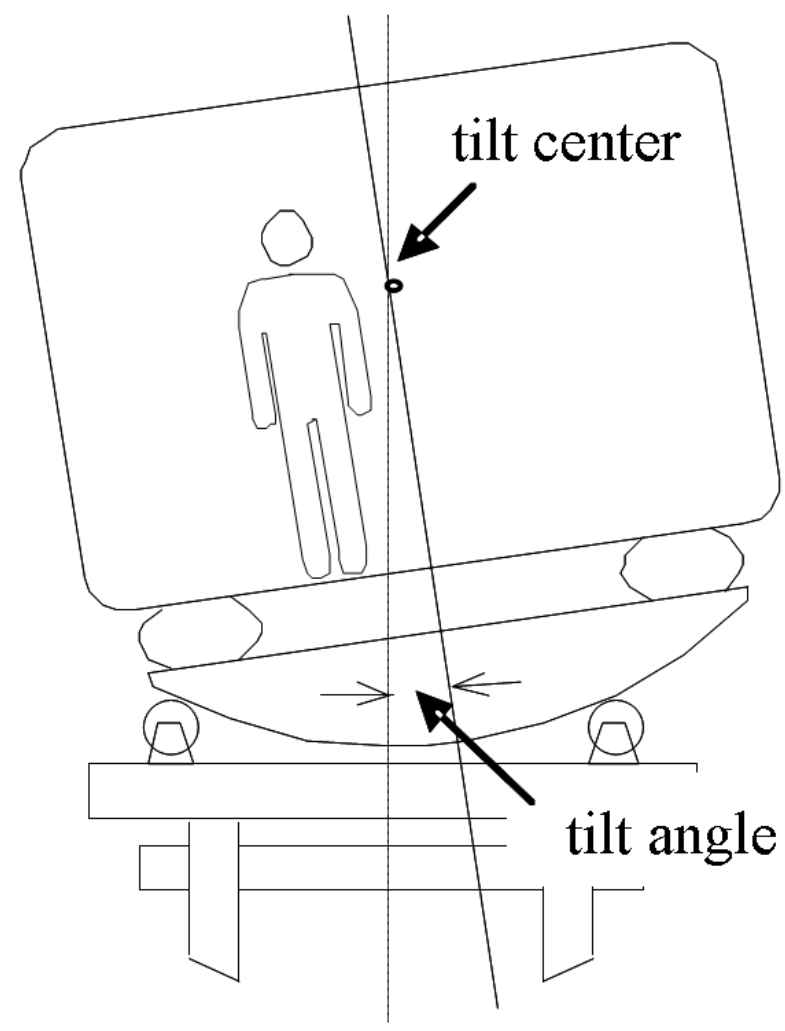

Figure 12. Natural tilt by circular guide

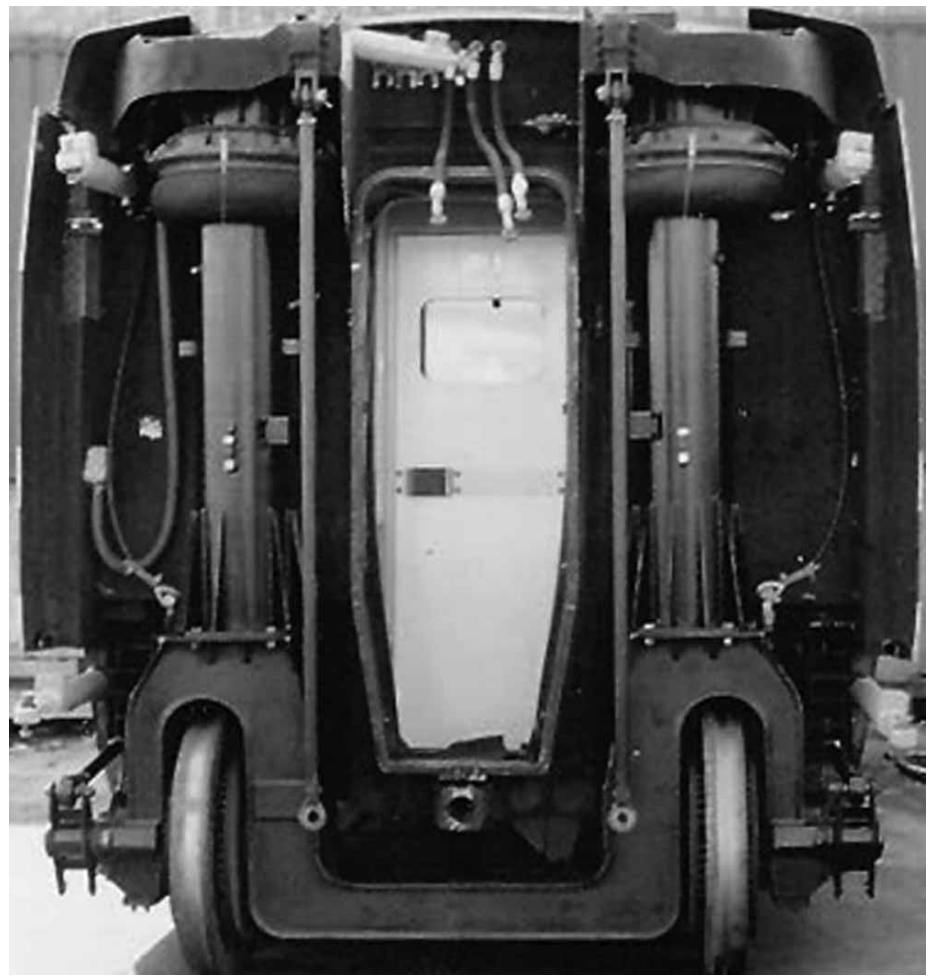

Figure 13. Natural tilt by high position air springs [20]. 


\subsubsection{Swing bolster with circular arc guide}

Swing bolster with circular arc guide is a common solution in Japanese tilting train. A tilting control system with pneumatic actuators is often added. In this system, the bogie has a swing bolster (also called tilting bolster), which allows motion in a circular path. The carbody is fitted on the tilting bolster, thus the carbody can tilt around the centre of the circular path of the tilting bolster. When the lateral acceleration acts on the carbody, it moves along the circular path and takes a tilt angle, which balances the lateral acceleration and moment created by the gravity times the lateral shift. In this tilting, the part of the lateral acceleration and the part of the gravity acceleration along the car floor will cancel each other as in Figure 12. Usually, the tilting centre is designed to the height of a sitting passenger's head. The carbody centre of gravity is about $60-900 \mathrm{~mm}$ lower than the tilting centre.

There are two types of tilting mechanisms. One consists of a tilting bolster, which has circular arc shape on the bottom surface and support rollers. The tilting centre becomes as the cross point of normal lines of the circular arc on the tilting bolster. Figure 14 shows the bottom of the bolster and the support rollers. The other type uses bearing guides, which are part of circular arc guide rail; Figure 15 shows this second type. Both types have dust proof seals. Dust seals are very important to keep equipment in good condition as the tilting bolsters otherwise collect dust on its long movable range.

The tilting resistance of this system is very small. Thus, tilting dampers are installed between the bogie frame and the tilting bolster to limit overshooting caused by moment of inertia of the carbody. Also from the view point of tilting delay in transition curve section, it is desirable that the tilting resistance is small. The damping coefficients of the tilting dampers are selected to be only about $20 \mathrm{kNs} / \mathrm{m}$. The characteristic of the tilting damper is decided by the trade-off between motion overshoot and tilting delay in transition curves.

To limit the tilting angle of the carbody to a safe range, stops movable by pneumatic actuators are installed on bogie frame. When the train speed is higher than $50 \mathrm{~km} / \mathrm{h}$, the stops disengage and allow the carbody to tilt $\left(5-6^{\circ}\right)$. For lower speeds, the stops engage and keep the carbody straight to prevent unwanted rolling particularly in station yard turnouts.

The merits of swing bolster with circular arc guide type are as follows:

(1) Small tilting resistance for tilting. Figure 16 shows the lift of the mass centre of carbody of this type in comparison with inclined link type tilting mechanism, which is common in the active tilting system (Figure 3, right). The carbody is hung from the bogie frame by a set of inclined links in the four-node link type tilting mechanism. The links are shorter than the distance to the virtual centre of tilting, which is determined as cross point of extended lines of links. The mass of the carbody is, therefore, raised up by the tilt motion. There is also a lateral shift of the tilt centre that increases the resistance to tilt, which makes this arrangement unsuitable for natural tilting. In contrast to the case of the inclined link type, the carbody mass lift with the swing bolster is small. Thus, this system effectively compensates the centrifugal acceleration in circular curve sections. In spite of the above mentioned, this system also has a time lag for tilting by the inertia of the carbody.

(2) In this system, the tilting bolster isolates some of the lateral vibrations in the bogie. Therefore, the lateral vibrations in the carbody are reduced compared with non-tilting trains in the high frequency range. 


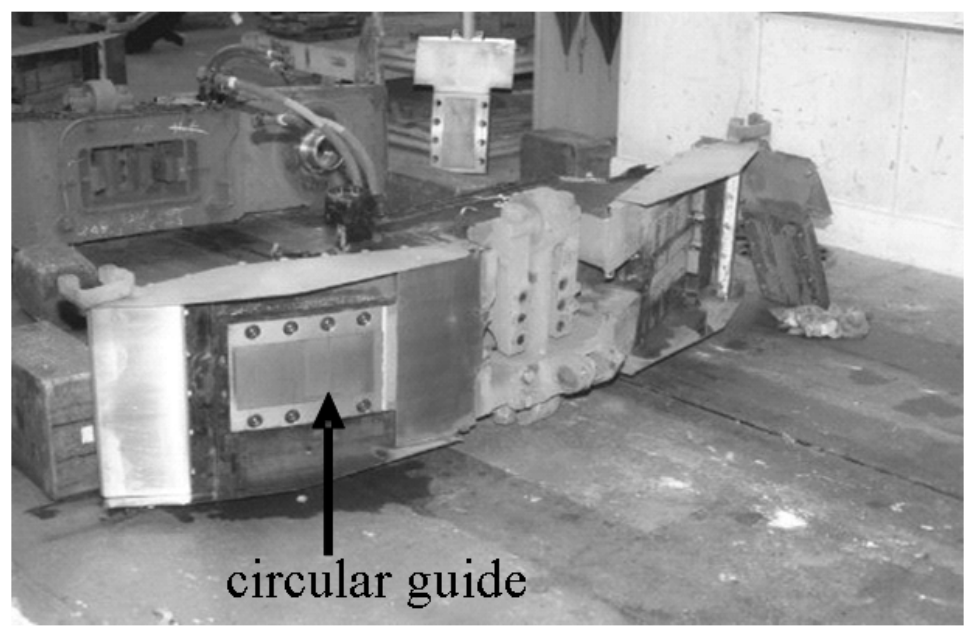

Tilting Bolster (from below)

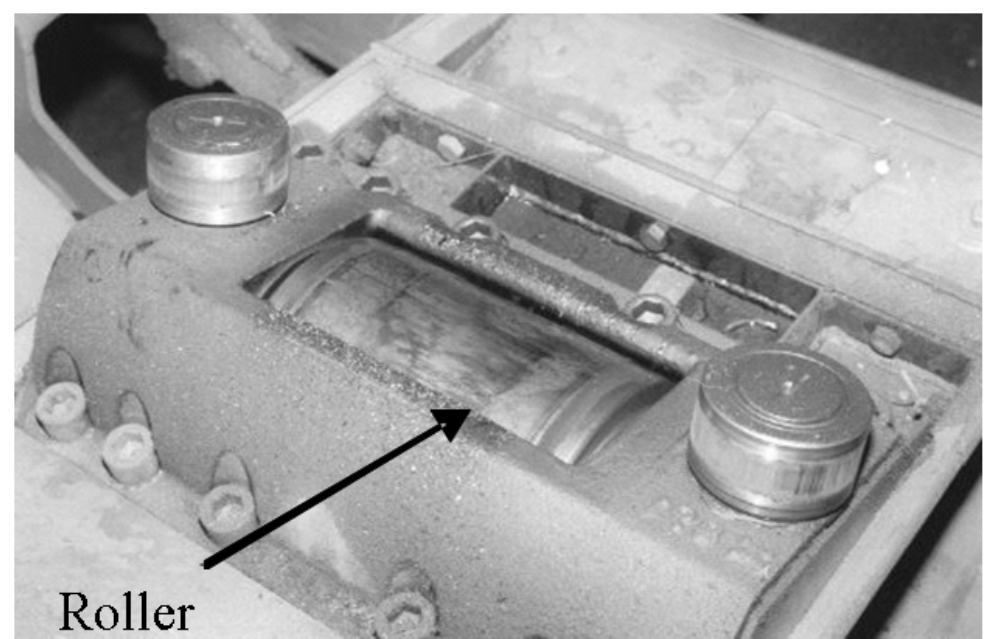

\section{Roller}

Figure 14. Tilting bolster and rollers

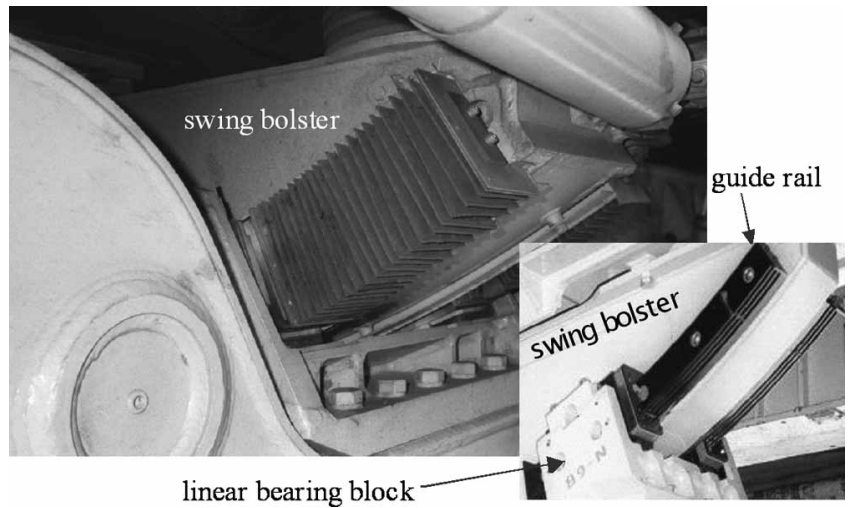

Figure 15. Bearing guide device 


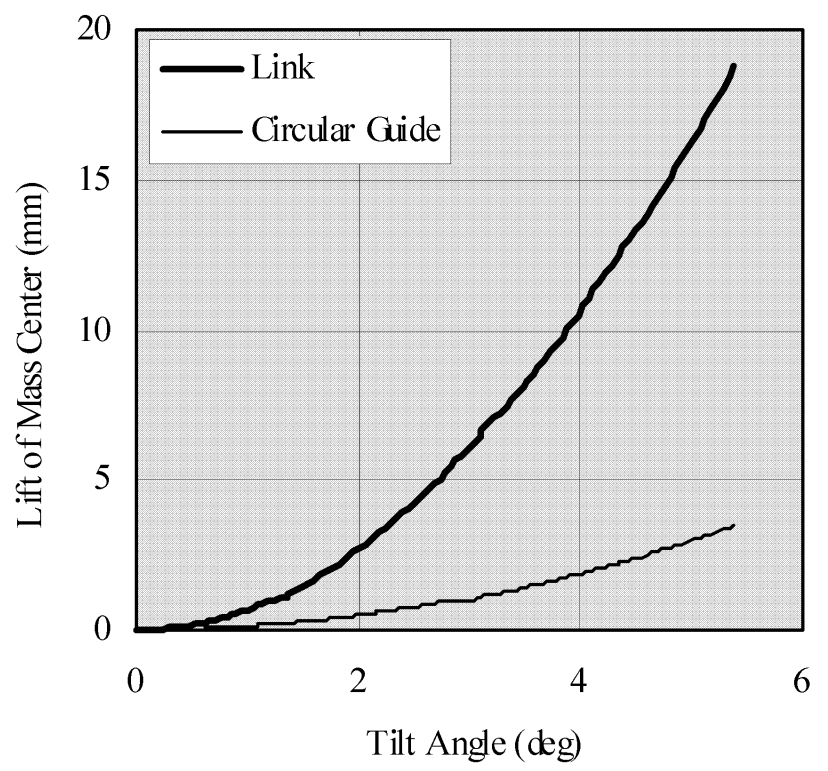

Figure 16. Comparison of mass center lift

The demerits of swing bolster with circular arc guide type are as follows:

(1) The feature of small tilting resistance is a significant merit for natural tilting, but it also brings some demerits on the characteristics of dynamics. Caused by the low damping of the tilting bolster, low-frequency lateral motions of the tilting bolster often appear. Also yaw motion with the two tilting bolsters out of phase may occur. In this mode, the difference in tilt angle on the front and rear tilting bolster is absorbed by secondary suspensions. Thus the damping for this yawing mode becomes small. In addition, the swing bolster solution has a tendency of tilting motion overshoot in short transition curves compared with the tilt angle in the circular curve. Figure 17 shows the tilt overshoot at the end of the transition curve. Therefore, the tilting train with swing bolster will have a tendency to increased low-frequency carbody motions.

(2) The structure of the bogies of this type is more complex than non-tilting bogies, and it has several movable parts, which increases the maintenance work. Especially, electric corrosion of the guide mechanism on electric trains is a particular problem of this system. On electric trains the current returns to the rail through the bogie frame. If the current passes the guiding devices, it melts the contact point such as rollers or bearings, liners and makes their surfaces rough. Normally, this phenomenon appears in the neutral position. As a result, the tilting resistance increases and the smooth movement of the tilting mechanism is spoiled by the sharp change of tilting resistance around the neutral position. The dust proof seals are another point which needs particular attention to maintain the performance of the tilting mechanism.

\subsubsection{High position air spring type}

This type of tilting system supports the carbody from a high position (Figure 13). The suspension arrangements of this system depend on the unique design of the Talgo train. A pair of air springs, also serving as secondary suspension, is installed on high pillars on the running gear. A connecting pipe and a control valve are installed between the two air springs. Normally, the control valve is shut and the 

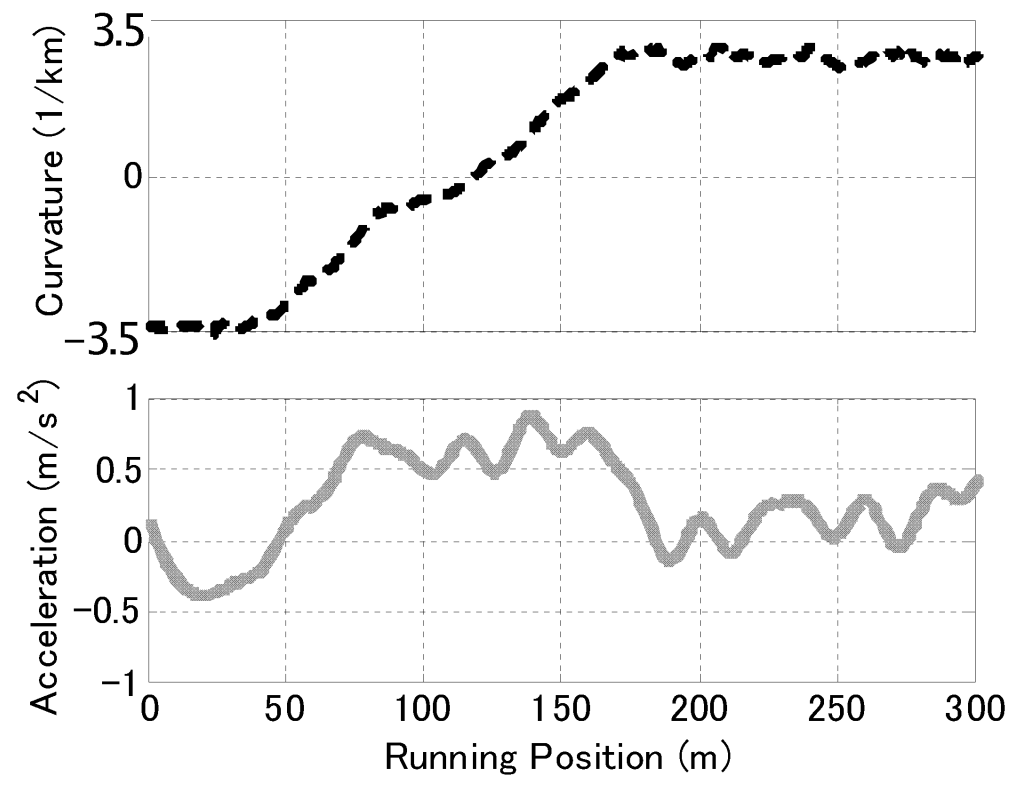

Figure 17. Lateral acceleration in S-curve transition

two air springs work independently such that the carbody has some roll stiffness. When the train runs in curve sections, the air springs are connected by opening the control valve. The air can now flow freely between the two air springs, and the rolling stiffness of the carbody is small. The centrifugal acceleration will force the carbody to tilt around the centre of the air springs. This function does not alter the vertical stiffness of the secondary suspension.

The Talgo train is based on articulated running gear technology having one set of air springs on one end of the car. The carbody on the opposite end is connected to next carbody by links with a bell crank mechanism; the vertical links are visible in Figure 13. This mechanism allows roll motion and tilt of one car is not influenced by the tilt of the adjacent car.

Its simple structure is a merit by realising natural tilting without any complex devices or mechanism. The control system is also simple. On the other hand, the most important demerit of this system is the difficulty of applying it to trains with conventional bogies. Installation in such trains will cause passenger space intrusion.

\subsection{Reducing the risk of motion sickness}

Motion sickness is discussed in Section 4.2 where lateral accelerations in the frequency range of $0.25-0.32 \mathrm{~Hz}$ are shown as most provocative for motion sickness in natural tilting trains. Table 2 shows the resonant frequencies of a natural tilting train. Note that the resonant frequency caused by tilting mechanism is included in the most susceptible frequency range of the motion sickness. In addition, although the natural tilting works well in the circular curve sections, the curve transitions cause low-frequency lateral acceleration by delay or overshoot of the tilt motion. When the train runs in a curve section, fluctuations of the lateral acceleration appear twice in each curve. The fluctuations of the acceleration tend to have a frequency similar to the frequency where the highest sensitivity for the motion sickness has been showed. These motions are caused by short transition curves existing on many narrow gauge lines in Japan.

The effect of the low-frequency acceleration for the motion sickness was understood when the tilting system was developed and actions were taken to reduce 
Table 2. Typical resonant frequencies of a natural tilting train.

\begin{tabular}{lc}
\hline Vehicle body vibration & Resonant frequency $(\mathrm{Hz})$ \\
\hline Lateral mode caused by air spring & 0.65 \\
Roll mode caused by air spring & 0.56 \\
Yaw mode caused by air spring & 0.89 \\
Roll mode caused by tilt & 0.27 \\
\hline
\end{tabular}

the risk of motion sickness. Particularly, a control system was introduced to the natural tilting system. The main purpose with control is to reduce the fluctuation of lateral accelerations in the transition curves. This control system is now part of most natural tilting systems in Japan. This combination is named controlled natural tilting.

The system is similar to the active tilt system, but with a much lower force requirement. A pneumatic cylinder is used as an actuator installed between the truck frame and the tilting bolster. The maximum force of the actuator is less than $7 \mathrm{kN}$ making the actuators unable to tilt the carbody against to the natural tilting force. One advantage with this solution is that tilting is still available in case of control failure, even though with reduced performance.

Figure 18 shows the configuration of the tilt control system. An onboard computer stores data and location of the curves of the lines. A train position detection system utilising the ground coils of the ATS (automatic train stop) system shows the absolute location of the train, and an integrated tachometer signal is used to get the running distance from the ground coils.

The system is able to start the tilting motion before entering the curves by preview control using the onboard database. This method reduces the tilting delay significantly and the overshoot is also reduced by the tilt control. The magnitude of frequencies with the largest sensitivity to motion sickness has been reduced and so also the number of motion sick passengers.

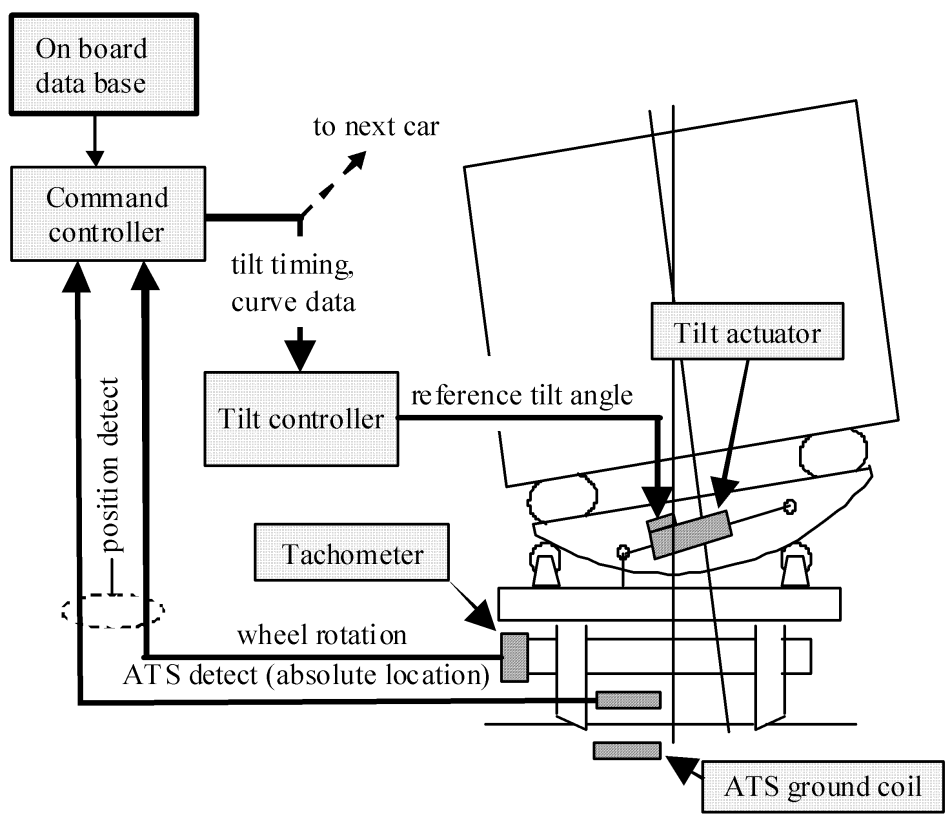

Figure 18. Structure of controlled natural tilting. 


\section{Human response}

\subsection{Passenger ride comfort}

Passenger comfort can be several things, but is here limited to the passenger ride comfort excluding motion sickness; this subject is thoroughly reported by Griffin[21]. There are two important relations to passenger ride comfort where tilting trains differ from non-tilting ones:

(1) Ride comfort as function of speed.

(2) Ride comfort as function of cant deficiency.

\subsubsection{Ride comfort as function of speed}

The present technique to evaluate average ride comfort implies measuring of carbody accelerations and frequency weighting of the measured signals. Weighting curves valid in the three directions can be found in International Standards Organization (ISO) [22], the weighting curve for lateral accelerations is shown as example in Figure 19. Weighted accelerations up to $0.3 \mathrm{~m} / \mathrm{s}^{2}$ r.m.s. are considered as comfortable according to the European Committee for Standardization (CEN) [23].

The ride comfort influenced by the vibrations and motions of the vehicle generally deteriorates with increased speed. And as a tilting train may run faster than a nontilting train on the same track, the ride comfort may, therefore, be worse. Worse ride comfort does not fit well to passenger expectations of a faster train and must be counteracted by reduced vibration transfer from track to passenger, i.e. improved vehicle suspension.

\subsubsection{Ride comfort as function of cant deficiency}

Increased cant deficiency has a relation to the quasi-static lateral acceleration perceived by the passenger, but the negative impact of high cant deficiency is balanced by the carbody tilt in tilting trains. However, carbody tilt increases the carbody roll motions which also may cause discomfort, and there is a trade-off to be reached between minimising the steady lateral acceleration on curves and ensuring comfortable response on the transitions. Combined criterion on quasi-static lateral acceleration, lateral jerk and roll velocity perceived by the passenger is given by CEN [23] in the $P_{C T}$ criterion.

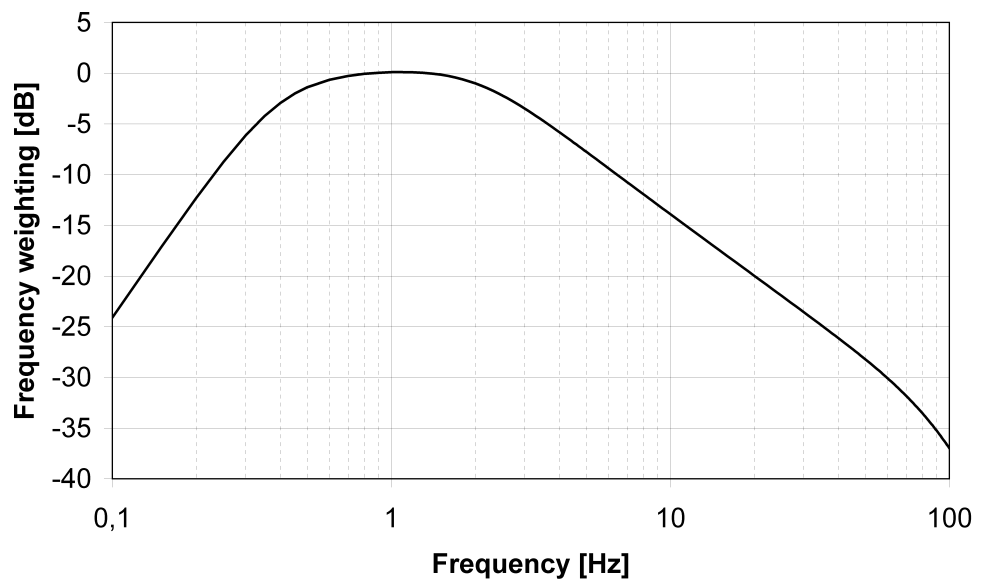

Figure 19. Normalised weighting function for lateral acceleration to comfort [22]. 
Table 3. Constants for $P_{\mathrm{CT}}$ comfort index.

\begin{tabular}{lcclll}
\hline Condition & $A\left(\mathrm{~s}^{2} / \mathrm{m}\right)$ & $B\left(\mathrm{~s}^{3} / \mathrm{m}\right)$ & $C(-)$ & $D\left(\mathrm{~s} /{ }^{\circ}\right)$ & $E(-)$ \\
\hline Standing & 0.2854 & 0.2069 & 0.111 & 0.00185 & 2.283 \\
Seated & 0.0897 & 0.0968 & 0.059 & 0.0012 & 1.626 \\
\hline
\end{tabular}

The $P_{C T}$ Comfort index for comfort on curve transitions is calculated on the basis of Equation (5) with constants according to Table 3:

$$
\left.P_{C T}=100 \cdot\left\{\max \left[A \cdot\left|\ddot{y}_{1 s}\right|_{\max }+B \cdot\left|\dddot{y}_{1 s}\right|_{\max }-C\right) ; 0\right]+\left(D \cdot\left|\dot{\varphi}_{1 s}\right|_{\max }\right)^{E}\right\},
$$

where $P_{C T}$ is the percentage of dissatisfied passengers, $\ddot{y}_{1 s}$ the lateral acceleration in carbody (average over $1 \mathrm{~s})\left(\mathrm{m} / \mathrm{s}^{2}\right), \dddot{y}_{1 \mathrm{~s}}$ the lateral acceleration change over $1 \mathrm{~s}$ in carbody $\left(\mathrm{m} / \mathrm{s}^{3}\right)$ and $\dot{\varphi}_{1 \mathrm{~s}}$ the roll velocity in carbody (average over $\left.1 \mathrm{~s}\right)(\mathrm{deg} / \mathrm{s})$.

Suzuki et al. [24] developed the $T C_{T}$ comfort index based on tests in Japan. This method is similar to the $P_{C T}$ comfort index, but there are some differences related to the experience in the origin countries.

(1) The $T C_{T}$ index is derived from curve entries and curve exits, the $P_{C T}$ index from curve entries only.

(2) The $T C_{T}$ index includes roll acceleration as parameter.

(3) The $P_{C T}$ index has a threshold (constant $\mathrm{C}$ in Table 3) below which discomfort is not considered.

These differences are not believed to alter the conclusions derived significantly. In principle, these indices provide the opportunity to ensure that a tilting train offers the same comfort level at the enhanced speed through curve transitions as a conventional train at the lower non-tilting speed. However, they may be contradictory to requirements on low risk of motion sickness as these indices favour low lateral acceleration, which may be achieved by increased roll angle which is known to increase the risk of motion sickness.

\subsection{Motion sickness}

\subsubsection{Evidence of motion sickness}

Evidence of motion sickness on non-tilting trains has been reported by several observers. Kaplan [25] reported that $0.13 \%$ of the passengers got motion sick among 370,000 passengers on the Baltimore and Ohio Railroad. Suzuki et al. [26] reported that $18 \%$ of the passengers experience motion sickness on non-tilting trains. The data comes from a large passenger survey made on 14 different types of trains on the conventional narrow-gauge Japanese network.

Evidence of motion sickness in tilting trains has been reported in Japan by Ueno et al. [27], in Sweden by Förstberg [28], in Switzerland by Hughes [29] and in France by Gautier [30]. Ueno et al. reports that as high as $27 \%$ of the passengers experience motion sickness on the naturally tilted train JNR class 381 . Forstberg [28] reports $6 \%$ motion sickness at a test on X2000 in Sweden and 8.15\% motion sickness in a test involving different tilt control strategies [31]. Tilting trains generally cause more motion sickness than non-tilting ones. However, the speed of the tilting trains was higher than for the non-tilting trains in reports where both types were considered. 


\subsubsection{Hypothesis of motion sickness}

The sensory conflict is the most common explanation of motion sickness. The different sensitive capabilities of the different human motion information sources give a sensory conflict, such as:

- a passenger sitting in a moving train and looking inside the train feels the movements but cannot see any,

- a subject in a simulator without moving platform sees movements on displays, but cannot feel any,

- a passenger sitting in a turning aircraft and making head movements feels the turning of the aircraft but cannot see any.

The theory has developed over the years from Claremont [32] and Reason and Brand [33] to today being able to explain most motion sickness cases. Benson [34] has included the central nervous system and expresses the conflict as:

That in all situations where motion sickness is provoked, there is a sensory conflict not only between signals from the eyes, vestibular organs and other receptors susceptible to motion, but also that these signals are in conflict with what is expected by the central nervous system.

One model of the conflict theory is given by Bles et al. [35] (Figure 20). The model consists of two paths, the top path represents the actual information from the sensors processed by the central nervous system, and the lower path represents the internal model, which estimates the effect of a given motion command (active motions). The estimated and the actual information are compared, and a conflict signal will be generated if they differ. Habituation is represented in the model by the feedback from conflict to the internal model; this feedback will then update the internal model. Passive motions (without motion command) are in the model represented by external influence; these can by themselves create conflict as the external influence do not have any direct influence on the internal model. Active motions may under influence of external motions result in conflict.

The conflict can also be described by the difference between the sensed direction and the expected direction of vertical. The conflict is described by Bles et al. [36] as:

Situations which provoke motion sickness are characterized by a condition in which the sensed vertical as determined on the basis of integrated information from eyes, the vestibular system and the non-vestibular proprioceptors is at variance with the subjective vertical as expected from the previous experience.

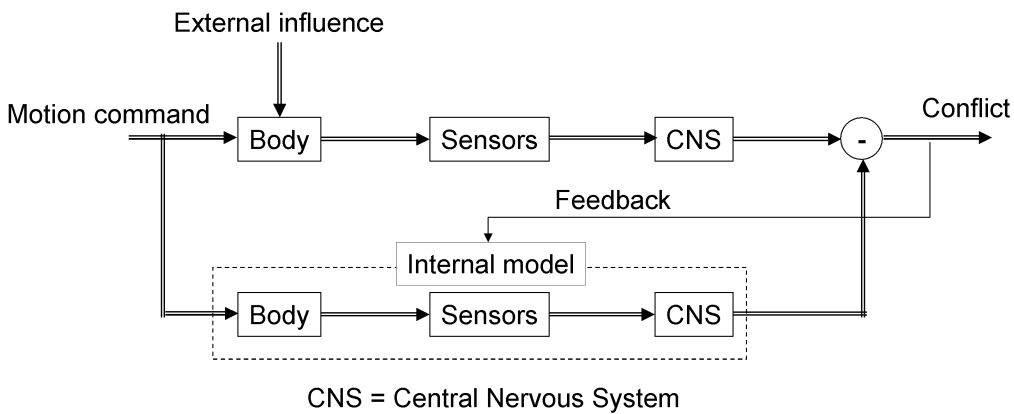

Figure 20. Model of the conflict theory, modified from Bles et al. [35]. 


\subsubsection{Frequency dependence of motion sickness}

O'Hanlon and McCauley [37] derived a relationship of motion sickness incidence (vomiting) to motion frequency and amplitude. This relationship became the basis for the weighting function, $W_{f}$, for pure vertical acceleration causing motion sickness, documented by ISO [22] (Figure 21). The function is primarily applicable to standing or seated passengers exposed to motions in ships and other sea vessels. However, it has also been used in other applications and in other directions.

Donohew and Griffin [38] proposed a weighting function for the lateral direction. The result was based on laboratory tests with pure lateral motions. The weighting function in lateral direction has the greatest sensibility between 0.02 and $0.25 \mathrm{~Hz}$ (Figure 22). Suzuki et al. [26] has investigated the relation of the motion sickness of the train passengers and various conditions for Japanese commercial lines. The investigation has been done for natural tilting trains with controlled activation as this is the most common type of tilting trains in Japan. Suzuki derived a relation between the percentage of persons who felt absolutely dreadful and weighted lateral acceleration. This weighting function has the greatest sensibility between 0.25 and $0.32 \mathrm{~Hz}$ (Figure 22). The differences between the two weighting curves shown are believed to be related to the roll mode dominance for natural tilting trains.

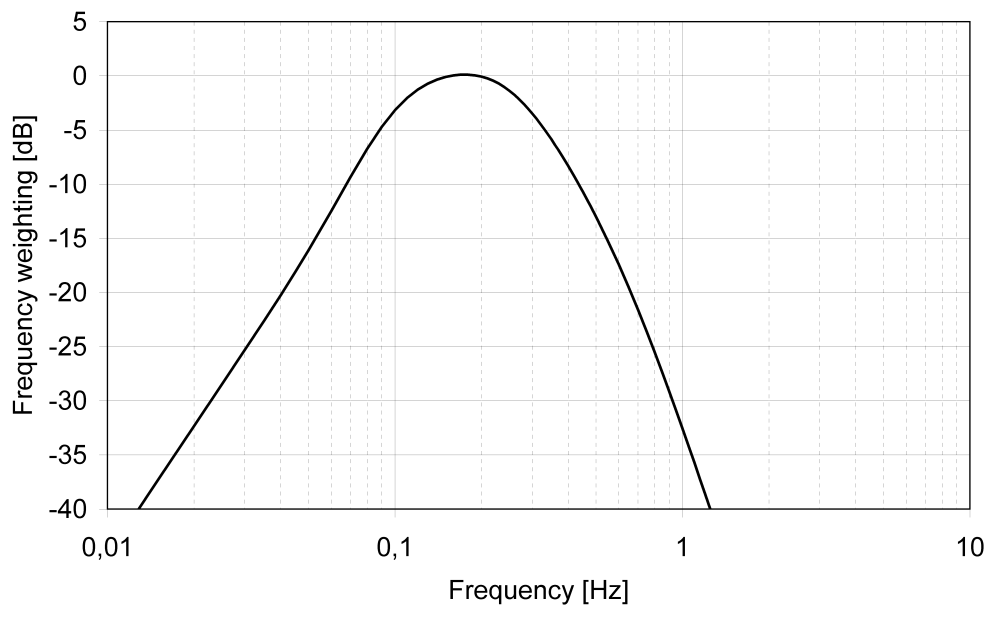

Figure 21. Normalised weighting function for vertical acceleration to motion sickness [22].

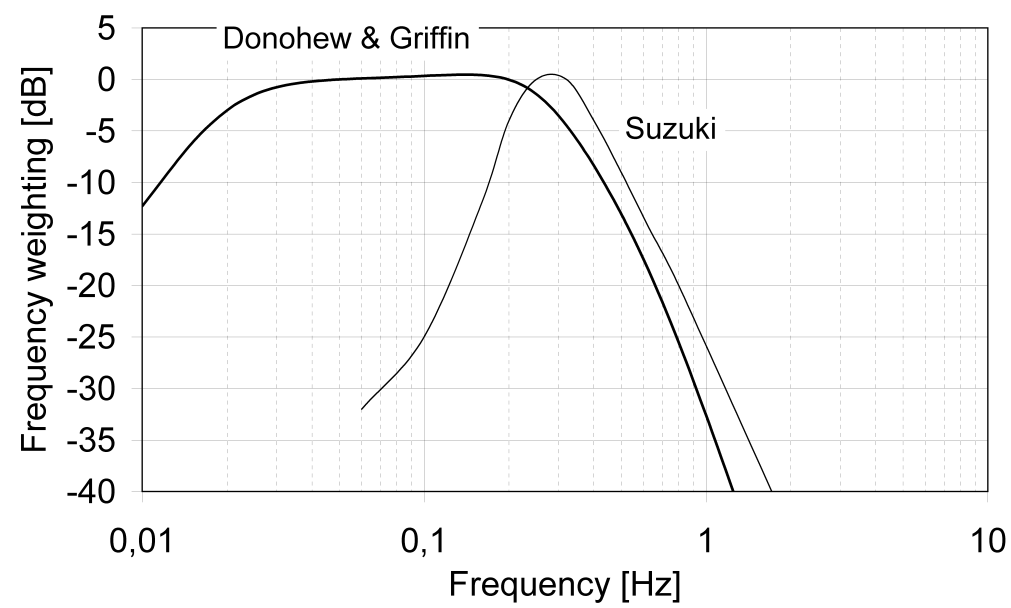

Figure 22. Normalised weighting functions for lateral acceleration to motion sickness $[26,38]$. 


\subsubsection{Time dependence of motion sickness}

There is a complex time dependence involved with motion sickness, different at fall ill and recovery. ISO [22] has taken a simplified approach in the motion sickness dose value (MSDV) dependence of time indicating the vomiting frequency in percent (Equation (6))

$$
M S D V_{z}(t)=k_{M S D V} \cdot \sqrt{\int_{0}^{T} a^{2} w f(t) d t},
$$

where $a_{w f}(t)$ is the frequency-weighted vertical acceleration $\left(\mathrm{m} / \mathrm{s}^{2}\right)$ and $k_{M S D V}$ $=1 / 3\left(\mathrm{~s}^{1.5} / \mathrm{m}\right)$ for a mixed population of male and female adults. The MSDV value will always give a value increasing with time. Also Suzuki et al. [26] use Equation (6) together with the weighted lateral acceleration and this value is then denoted by $M S D V_{y}(t)$.

Kufver and Förstberg [39] derived the net-dose time dependence $\mathrm{ND}(\mathrm{t})$, which describes the motion sickness both at fall ill and recovery. The dependence is a first-order low-pass filter, which mathematically may be described as

$$
N D(t)=k_{N D} \cdot \int_{-}^{T} a_{w f}(t) \cdot e^{k \cdot(t-T)} \cdot d t
$$

where $a_{w f}(t)$ is the frequency-weighted vertical acceleration $\left(\mathrm{m} / \mathrm{s}^{2}\right), k_{N D}=$ constant $(\mathrm{s} / \mathrm{m})$ and $\mathrm{k}=$ constant $(1 / \mathrm{s})$. The net-dose will follow the actual degree of motion sickness.

Both the MSDV and the net-dose may be used with other signal input than vertical acceleration; examples are lateral acceleration and roll velocity.

Habituation is also a kind of time dependence of motion sickness. This ability has been observed since long time at sea. Habituation is made to one specific environment while other motions may still cause motion sickness. Most researchers have reported time constants for habituation in the range of 3-5 days, but the effect can also be observed after a few hours [25]. Habituation has been observed at motion sickness tests on tilting trains where test subjects recover from motion sickness at maintained stimuli.

\subsubsection{Measured motion quantities}

Figure 23 shows power spectral density (PSD) diagram of the roll acceleration, which is one of the motion components with large difference between tilting and non-tilting trains. A four car long-distance tilting train, class BM73, from Norwegian State Railways was used as test train. The non-tilting cases were run with the same train, but with the tilt inactive. It should be noted that the non-tilting test cases were run at a lower speed than the tilting cases. The measurements are taken on the Norwegian line between Kristiansand and Vegårdshei. For roll acceleration the main difference is found between 0.02 and $0.5 \mathrm{~Hz}$, where the tilting train shows larger magnitudes than the non-tilting one. Vertical acceleration shows similar differences. The main difference for lateral acceleration is found below $0.05 \mathrm{~Hz}$ where the non-tilting train shows larger magnitudes than the tilting one. The three remaining motion components show no significant differences. PSD-diagrams for all six motion components are shown in Persson [40].

\subsubsection{Measured motion quantities - experienced motion sickness}

Laboratory tests have proven that translations in all directions can cause motion sickness. Pure rotations seem to have less correlation to motion sickness than 


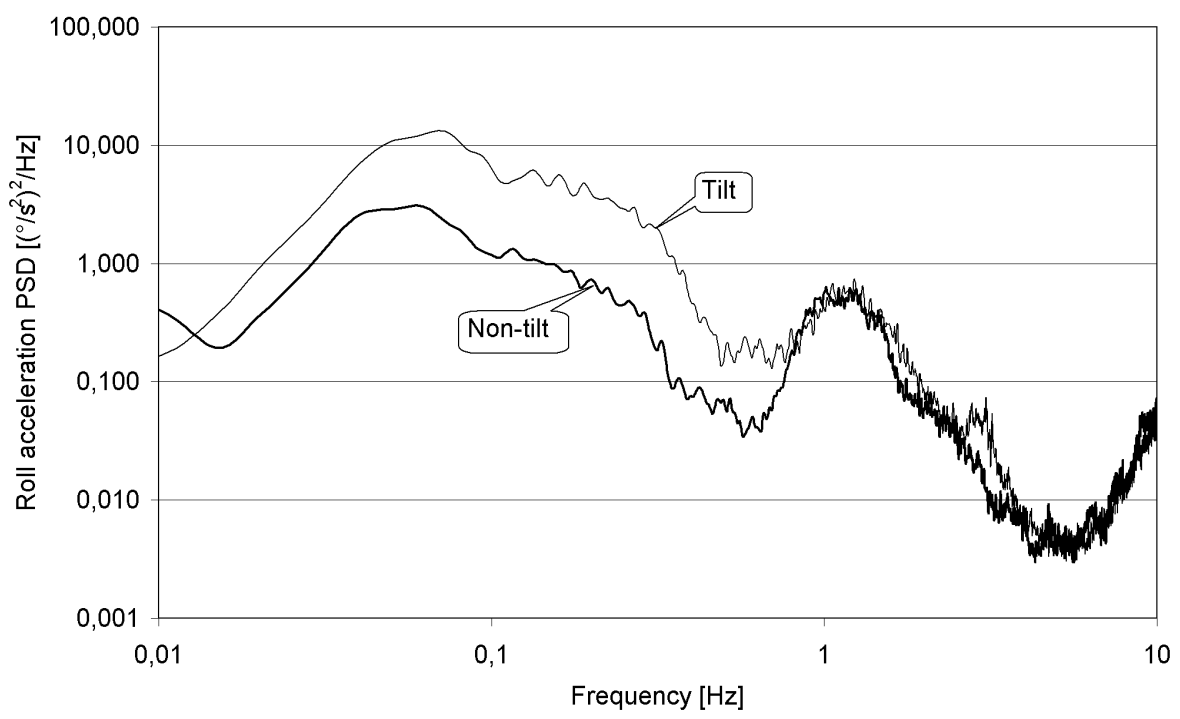

Figure 23. Carbody roll acceleration in tilting and non-tilting train, also the non-tilting case was made with a tilting train but without compensating the lateral acceleration [40].

translations. However, all the laboratory tests causing motion sickness have been performed at amplitudes higher than measured in tilting trains. The laboratory tests cannot, therefore, explain the motion sickness experienced in tilting trains. It is likely that combinations of motions, in particular translation combined with rotation, contribute to the motion sickness experienced in tilting trains as these combinations have proven to be highly effective in provoking motion sickness in laboratories.

\section{Track - vehicle interaction}

\subsection{Track forces}

Track forces are a natural part of the homologation process for railway vehicles. Standards give guidance on track shift forces, derailment ratio, lateral wheel forces and vertical wheel forces (Figure 24). The track forces are normally measured with measuring wheelsets to show compliance with the requirements. The standards also give guidance on how to select suitable track sections for the measurements and how to process the measured forces. The standards are normally considering three quantities to be safety critical; the risk of shifting the track laterally, the risk of derailing due to flange climbing and running stability. Quantities related to track fatigue as the lateral and vertical track forces are normally also considered.

\subsubsection{Track shift force}

The track shift force is the sum of lateral wheel forces on a wheelset, $\mathrm{S}$ ( $\sum \mathrm{Y}$ in some countries) in Figure 24. The track shift force is related to the risk of shifting the track laterally when a train passes. The criterion is also known as the Prud'homme criterion after the inventor [41].

The track shift force can be divided into two parts, one quasi-static part and one dynamic part. The quasi-static part has a dependence of cant deficiency, which for a tilting train is higher than for a non-tilting train. The dynamic part has a dependence of speed, which (for the same curve radius) is also higher for a tilting train than for a non-tilting train, presupposed that no improvement is made in the running gear and suspension. 


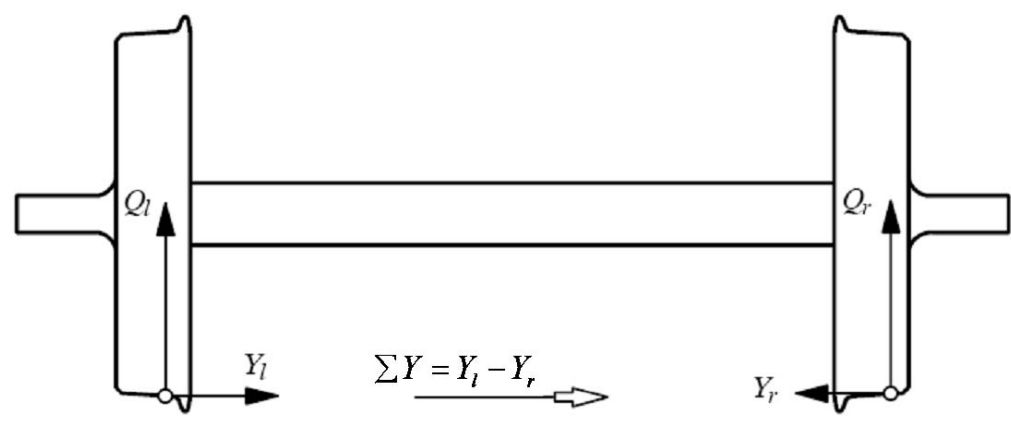

Figure 24. Definitions of track forces.

Important factors for maintaining the track shift forces under the specified limits are [42]:

- low static loads,

- low unsprung mass (impact on dynamic part),

- suspension characteristics (impact on dynamic part),

- radial steering (impact on force distribution between two axles in a bogie).

\subsubsection{Derailment criteria}

The ratio between lateral and vertical track forces on a wheel, $Y / Q$, is often used as derailment criterion, this ratio is also called flange climbing criterion. The lateral force on the flange is here balanced by the vertical force at the same wheel. The derailment ratio can be divided into two parts, one quasi-static part and one dynamic part. The quasi-static part has a dependence on cant deficiency, which for a tilting train is higher than for a non-tilting train, but both the lateral and vertical forces increase when the cant deficiency increases. However, the risk for derailment is larger at low speeds than in high speeds due to the influence from curve radii and track irregularities. The tilt is normally inactive at these speeds making tilting trains no different from the non-tilting train in this critical case.

\subsubsection{Stability criteria}

The track shift force can be used as stability criteria if evaluated as r.m.s over a certain track section. The track shift force is in this case band-pass filtered around the instability frequency. Instability has a dependence of speed, which may be higher for a tilting train than for a non-tilting one. Instability is not only a straight track problem as instability also may occur when negotiating curves with large radii at high speed. The requirements on running stability and track shift forces are also counteracting each other, as the suspension characteristics advantageous for track shift forces may be disadvantageous for running stability. This counteraction is particularly evident for high-speed tilting trains.

\subsection{Cross-wind stability}

Cross-wind stability is an area where much research is in progress. Different calculation methods have been suggested and applied by different scientists. Flange climbing is not considered as safety critical for cross-wind, since an increased lateral force is accomplished by an increased vertical force on the potentially climbing wheel. Cross-wind stability is rather considered by the risk of over-turning the vehicle (Equation (8)): 


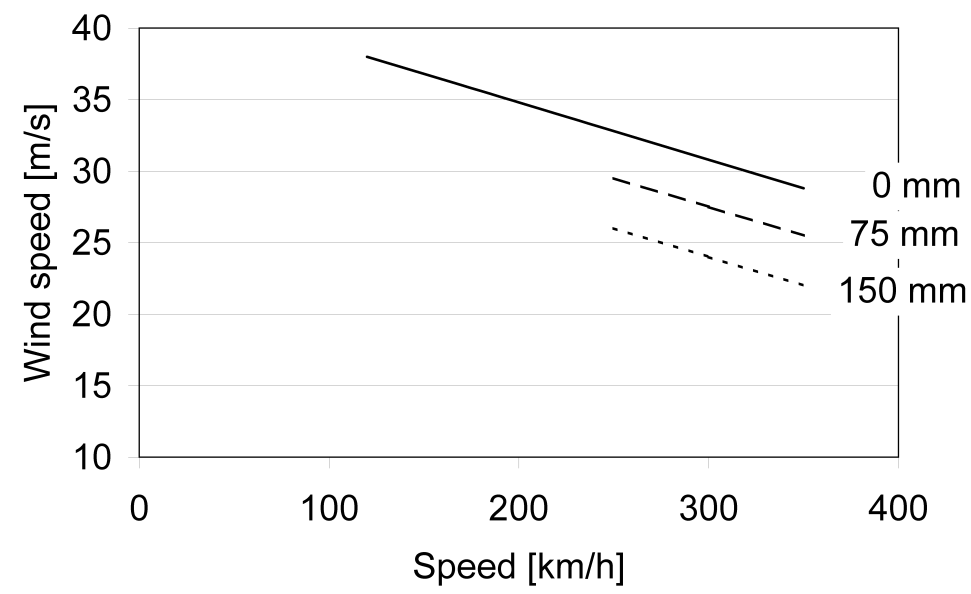

Figure 25. Characteristic wind curves as function of speed, for different cant deficiencies at standard gauge, in the flat ground case.

$$
\left(\frac{\Delta Q}{Q_{0}}\right)_{\max , \min }=0.9,
$$

where $\Delta Q$ is the average (dynamic) vertical wheel force reduction on the two unloaded wheels of a bogie and $Q_{0}$ the static vertical wheel force.

The Association Européenne pour l'Interopérabilité Ferroviaire has included guidance on cross-wind stability in a working draft of interoperability [43]. The draft does not explicitly treat tilting vehicles at enhanced speed. A comparative technique based on characteristic wind curves (CWCs) is described though. The CWCs show the maximum cross-wind as a function of speed (Figure 25), where the wheel unloading criterion (Equation (8)) is fulfilled. The selected reference vehicles are: the inter-city-express-3, the Train á Grande Vitesse Duplex and the ETR500 all being non-tilting high-speed vehicles. Any other vehicle used on the interoperable lines must have better or equal CWCs than the reference vehicles. It should be noted that extending AEIF requirements to the high cant deficiencies used by tilting trains would result in low critical wind speeds. A better approach would be to compare the tilting trains at their track cant deficiencies with the reference vehicles at their cant deficiencies.

AEIF [44] states that the infrastructure manager must for each interoperable line ensure that the conditions on the line are not more severe than what the reference vehicle can handle. Suggested measures in infrastructure and operations to ensure the safety are:

- locally reduced train speed, possibly temporary during periods at risk of storms,

- installing equipment to protect the actual track section from cross winds,

- or taking other necessary steps to prevent vehicle overturning or derailment.

Diedrichs et al. [45] showed the relation between different properties of a vehicle and crosswind stability. Studied properties for vehicles cross-wind stability were:

- train height,

- train width,

- carbody vertical centre of gravity,

- mass of leading bogie,

- nose shape, cross section shape and other properties that affect the aerodynamic 
coefficients of the vehicle,

- train speed,

- density of air (depending on air pressure and temperature).

The property with the strongest relation to cross-wind stability is the train height.

\section{Running time benefits}

\subsection{Theoretical benefits}

Theoretical running time benefits can be derived from the relations between enhanced permissible speed for tilting trains and the permissible speed for non-tilting trains. These requirements can be found in track standards. The types of requirements are similar in the standards, but the levels showa large variation, as can be seen in Table 4 where key requirements from certain standards are given.

The Fast And Comfortable Trains (FACT) project analysed the track standards in the view of running speed benefits for tilting trains [47]. The present analysis is an update.

In circular curves the relation between enhanced permissible speed for active tilting trains $V_{T}$ and the permissible speed for non-tilting trains $V_{C}$ may be expressed as

$$
\frac{V_{T}}{V_{C}}=\sqrt{\frac{D_{T}+I_{T}}{D_{C}+I_{C}}}
$$

where $D_{T}$ is the limit for cant, active tilting trains $(\mathrm{mm}) ; I_{T}$ the limit for cant deficiency, active tilting trains $(\mathrm{mm}) ; D_{C}$ the limit for cant, non-tilting trains $(\mathrm{mm})$ and $I_{C}$ the limit for cant deficiency, non-tilting trains $(\mathrm{mm})$.

From the track standards shown in Table 4, the relation between enhanced permissible speed for active tilting trains $V_{T}$ and the permissible speed for non-tilting trains $V_{C}$ can be found in the range $111-122 \%$.

On cant transitions, the relation between enhanced permissible speed for active tilting trains $V_{T}$ and the permissible speed for non-tilting trains $V_{C}$ may be expressed as in Equation (10):

$$
\frac{V_{T}}{V_{C}}=\frac{\dot{D}_{T}}{\dot{D}_{C}}
$$

where $D_{T}$ is the limit for rate of change of cant, tilting trains $(\mathrm{mm} / \mathrm{s})$ and $D_{C}$ the limit for rate of change of cant, non-tilting trains $(\mathrm{mm} / \mathrm{s})$.

From the track standards shown in Table 4, the relation between enhanced permissible speed for tilting trains $V_{T}$ and the permissible speed for non-tilting trains $V_{C}$ can be found in the range 85-131\%. Only Japan has more restrictive limits for tilting trains than for non-tilting trains.

On transition curves, the relation between enhanced permissible speed for active tilting trains $V_{T}$ and the permissible speed for non-tilting trains $V_{C}$ may be expressed as

$$
\frac{V_{T}}{V_{C}}=3 \sqrt{\frac{\dot{D}_{T}+\dot{I}_{T}}{\dot{D}_{C}+\dot{I}_{C}}},
$$

where $\dot{D}_{T}$ is the limit for rate of change of cant, active tilting trains $(\mathrm{mm} / \mathrm{s}) ; \dot{I}_{T}$ 
Table 4. Comparison between different standards on non-tilting and tilting vehicles.

\begin{tabular}{lccc}
\hline & CEN $^{\mathrm{a}}$ & National European $^{\mathrm{b}}$ & Japan \\
\hline General properties & & & \\
Cant (mm) & 160 & $139^{\mathrm{c}}-180$ & $141^{\mathrm{c}, \mathrm{d}}$ \\
Cant gradient (mm/m) & 2.25 & 2.50 & $3.36^{\mathrm{c}, \mathrm{e}}$ \\
Non-tilting vehicles & & & \\
Cant deficiency (mm) & 168 & $92-180$ & $67-94^{\mathrm{c}, \mathrm{d}}$ \\
Rate of cant (mm/s) & $50^{\mathrm{f}}$ & $35-85$ & $62^{\mathrm{c}, \mathrm{e}}$ \\
Rate of cant deficiency (mm/s) & 55 & $30^{\mathrm{c}}-100$ & $41^{\mathrm{c}, \mathrm{e}}$ \\
Natural tilting vehicles & & & $182^{\mathrm{c}}$ \\
Cant deficiency (mm) & - & $43^{\mathrm{c}}$ & $53^{\mathrm{c}, \mathrm{e}}$ \\
Rate of change of cant (mm/s) & - & $48^{\mathrm{c}}$ & $41^{\mathrm{c}, \mathrm{e}}$ \\
Rate of change of cant deficiency (mm/s) & - & & $148-165^{\mathrm{c}, \mathrm{d}}$ \\
Active tilting vehicles & & $245-300$ & $53^{\mathrm{c}, \mathrm{e}}$ \\
Cant deficiency $(\mathrm{mm})$ & 275 & $76-95^{\mathrm{f}}$ & $41^{\mathrm{c}, \mathrm{e}}$ \\
Rate of change of cant (mm/s) & $75^{\mathrm{f}}$ & & \\
Rate of change of cant deficiency (mm/s) & 100 & & \\
\hline
\end{tabular}

${ }^{\mathrm{a}}$ Recommended values in [46].

${ }^{\mathrm{b}}$ The national European column shows the spread of values according to Kufver [47]. Countries considered are The Czech Republic, France, Germany, Italy, Norway, Spain, Sweden and UK.

${ }^{\mathrm{c}}$ Equivalent for standard gauge.

d Japan ministry of land, infrastructure, transport and tourism.

e Japan Railway group.

${ }^{\mathrm{f}}$ The higher limit for active tilting vehicles compared with non-tilting vehicles is not understood by the authors of the present paper.

${ }^{\mathrm{g}}$ France and Germany have no limit.

the limit for rate of change of cant deficiency, active tilting trains $(\mathrm{mm} / \mathrm{s}) ; \dot{D}_{C}$ the limit for rate of change of cant, non-tilting trains $(\mathrm{mm} / \mathrm{s})$ and $\dot{I}_{C}$ the limit for rate of change of cant deficiency, non-tilting trains $(\mathrm{mm} / \mathrm{s})$.

From the track standards shown in Table 4, the relation between enhanced permissible speed for active tilting trains $V_{T}$ and the permissible speed for non-tilting trains $V_{C}$ can be found in the range $97-116 \%$. Only Japan has more restrictive limits for tilting trains than for non-tilting trains.

\section{2. $\quad$ Simulated benefits}

A more precise estimation of the running time benefit with tilting trains can be achieved with running time simulation. The running time benefit is derived by simulation on a selected track indicating a realistic running time benefit compared with non-tilting rolling stock. Simulations of running times given in this study are performed without any running time margin. Running time margins and dwelling times must be added to receive running times suitable for time tables.

Assumptions for the calculations are:

- enhanced speed compared with non-tilting train is allowed at the same track sections as today,

- the track cant is kept as installed today,

- the maximum speed is set depending on the cant deficiency only, i.e. the conditions at curve transitions are not considered,

- limitations due to possible cross-wind effects are not considered.

\subsubsection{The track}

The Stockholm-Gothenburg relation is suitable as an example, as this is one of the most important train services in Sweden. The track may be characterised by the curve distribution which here is given as percentage of the total length of the track. The curve distribution for the line is shown in Figure 26. The curve radius 
indicated is the mean radius in that group, for example the curves in group $1000 \mathrm{~m}$ range from 900 to $1100 \mathrm{~m}$. The Stockholm-Gothenburg line has a variety of curves ranging from $352 \mathrm{~m}$ radius and up. The length of the circular curves (transition curves are excluded) with radii less than $6000 \mathrm{~m}$ constitutes in total $19 \%$ of the line. The total length of this railway line is $457 \mathrm{~km}$.

\subsubsection{The train}

The basis for the running time simulations is a future train with key performance properties as shown in Table 5 . The tilting and the non-tilting trains only differ on the permissible cant deficiency. The top speed is also variable as higher speed is needed to utilise the increased cant deficiency of the tilting train.

The result of the running time simulations on Stockholm-Gothenburg can be seen in Figure 27, where the running times are given as function of cant deficiency. The stopping pattern includes four intermediate stops, but this has a quite limited impact on the difference between the different cant deficiencies. The four lines represent four trains with top speed ranging from 200 to $275 \mathrm{~km} / \mathrm{h}$. The running times improves with increased cant deficiency and with increased top speed as expected. The running time benefit between a non-tilting train with maximum cant deficiency of $168 \mathrm{~mm}$ and a tilting train with $275 \mathrm{~mm}$ maximum cant deficiency, both with top speed $275 \mathrm{~km} / \mathrm{h}$, is $10 \%$. Note that a non-tilting train with maximum cant deficiency of $168 \mathrm{~mm}$ and $275 \mathrm{~km} / \mathrm{h}$ top speed will also have longer running times than a tilting train with maximum cant deficiency of $275 \mathrm{~mm}$ and only $200 \mathrm{~km} / \mathrm{h}$ top speed.

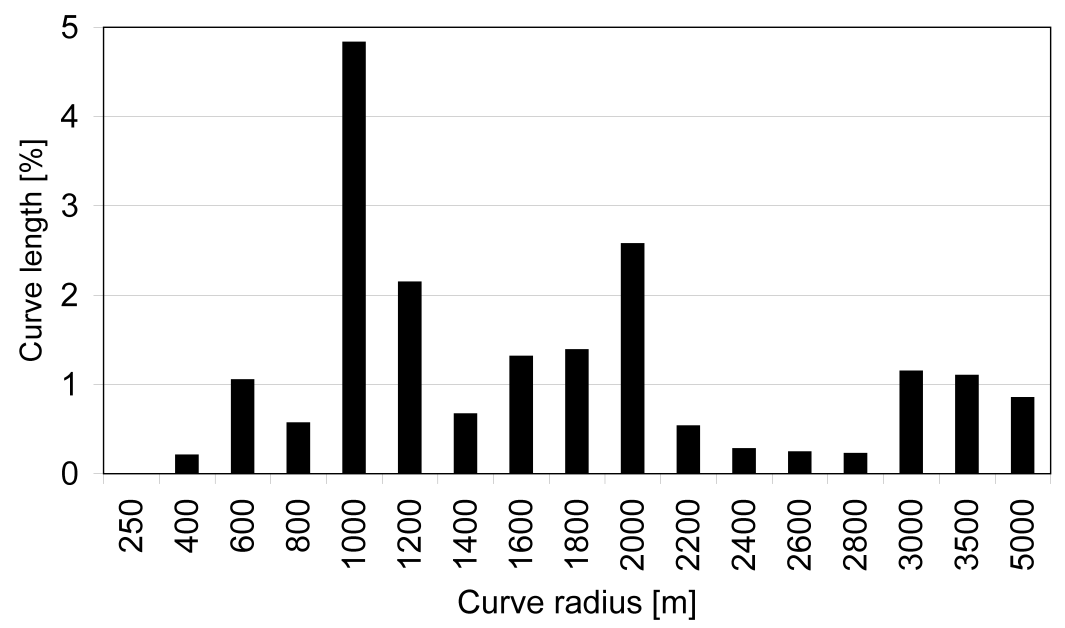

Figure 26. Distribution of circular curves (curve transitions excluded) with radii less than $6000 \mathrm{~m}$ as proportion of the total length of the line Stockholm-Gothenburg.

Table 5. Key performance properties for the train in the simulation.

\begin{tabular}{lc}
\hline Performance property & Value \\
\hline Number of vehicles $^{\mathrm{a}}$ & 6 \\
Cant deficiency $^{\mathrm{a}}$ & $100-300 \mathrm{~mm}$ \\
Weight with seated passengers & 360 tonne \\
Top speed in service & $200-275 \mathrm{~km} / \mathrm{h}$ \\
Short-term power & $6.0 \mathrm{MW}$ \\
Starting acceleration $^{a}$ & $0.6 \mathrm{~m} / \mathrm{s}^{2}$ \\
Braking deceleration & $0.6 \mathrm{~m} / \mathrm{s}^{2}$ \\
Running resistance & $R=2400+60 \cdot v+6.5 \cdot v^{2}(\mathrm{~N})$ where $v$ is the speed $(\mathrm{m} / \mathrm{s})$ \\
\hline
\end{tabular}

${ }^{\mathrm{a}}$ This property is variable. 


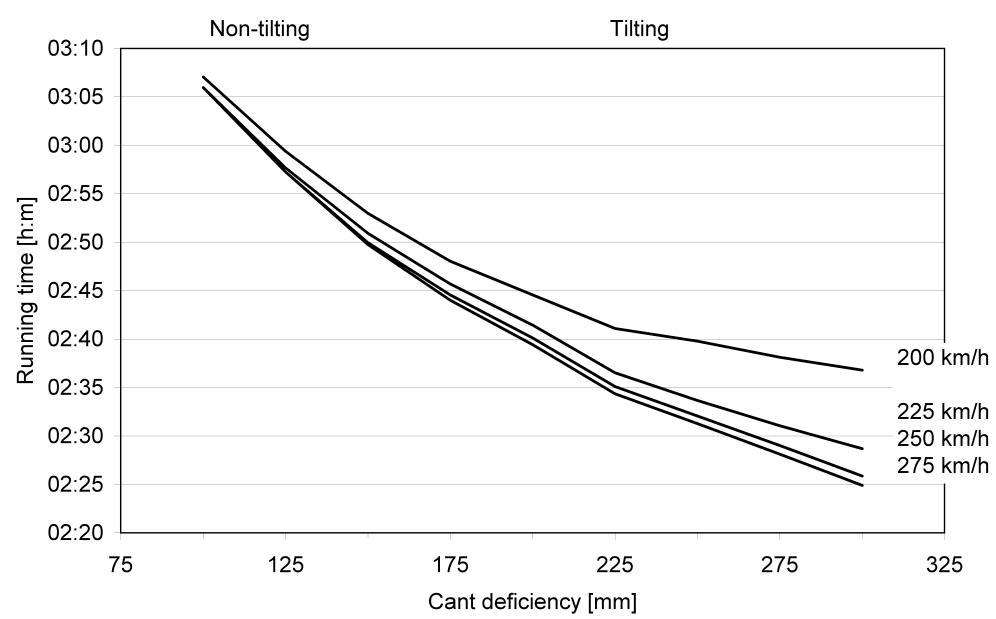

Figure 27. Simulated running times StockholmCGothenburg as function of cant deficiency with four intermediate stops for four different top speeds.

\section{Conclusion}

This paper has explained the concepts involved in carbody tilting and the associated technology development that has helped to establish it as a mature, commercially successful aspect of modern railway technology that is used world-wide to achieve valuable reductions in journey time.

Carbody tilting is today a mature and inexpensive technology allowing higher speeds in curves and thus reduced travel time. The technology is accepted by many train operators. Today more than 5000 tilting vehicles, defined as tilting carbodies, have been produced world-wide by different suppliers.

\subsection{Active tilting}

The mechanical solutions for active tilting involving pendulums or rollers are well proven. They have also become compact enough to avoid passenger area intrusion. Hydraulic and mechanic are the most popular means of actuation, even though pneumatics may be used for systems with limited tilt angles. Compact actuators, electro-hydraulic or electro-mechanic, placed in the bogie have become an alternative particularly when under-frame space is limited. Recent developments in control have provided the market with more clever systems erasing the former problem with time delays. These systems store track data, which combined with a positioning system, allow the train to calculate the optimum tilt angle in real time. The result is beneficial for both ride comfort and low risk of motion sickness.

\subsection{Natural tilting}

Natural tilting trains let tilting follow physical laws, like child swings. However, many of todays trains do have an active system to improve the control of the tilt motion. The mechanical arrangement may be similar to the active tilting arrangements, but with an adjusted relation between carbody height of centre of gravity and rotation centre. The actuation may in this case be much less powerful as physical laws still provides the main part of forces needed. Compact actuators are a natural choice for actuation. Natural tilting trains have in many respects lead the 
developments of control system for tilting trains. As early as in the late 1980s control systems utilising way side information were introduced in the natural tilting trains in Japan. The development was forced by requirements on ride comfort and low risk of motion sickness.

\subsection{Human response}

Increased cant deficiency has a relation to the quasi-static lateral acceleration perceived by the passenger, but the negative impact of high cant deficiency is in tilting trains balanced by the carbody tilt. However, carbody tilt increases the carbody roll motions which also may cause discomfort.

Laboratory tests have proven that translations in all directions can cause motion sickness; it is only a matter of magnitude and duration. Weighting curves exist as results from the laboratory tests, with sensitivity peaks at frequencies of $0.2 \mathrm{~Hz}$ or below. Pure rotations seem to have less correlation to motion sickness than translations. Combinations of motions, in particular translation combined with rotation, are highly effective in creating motion sickness.

Motion quantities measured in tilting trains differ from motion quantities measured in non-tilting trains by increased levels of vertical and roll motions at frequencies below $1 \mathrm{~Hz}$. These increased levels of motions may contribute to the difference in experienced motion sickness between non-tilting and tilting trains.

\subsection{Track/vehicle interaction}

Increased permissible cant deficiency of tilting trains may lead to reduced running times. However, potential limitations arise from lateral track shift forces and cross-wind stability. Exactly where the limits are is depending on both vehicle and infrastructure.

\subsection{Running times}

There is a trend to apply more and more track cant. Today, $180 \mathrm{~mm}$ track cant is allowed by some infrastructure managers on lines without freight traffic. High track cant increases the permissible speed for both non-tilting and tilting trains, but the difference in running time between non-tilting and tilting trains is decreasing. There is also a trend to allow more and more cant deficiency for non-tilting passenger trains, which also decreases the difference in running time between non-tilting and tilting trains. However, the increased cant deficiency will for the non-tilting train result in increased lateral acceleration perceived by the passenger.

As an example, running time simulations on Stockholm-Gothenburg have shown that the running time benefit between a non-tilting train, with maximum cant deficiency of $168 \mathrm{~mm}$, and a tilting train, with $275 \mathrm{~mm}$ maximum cant deficiency, both with top speed $275 \mathrm{~km} / \mathrm{h}$, is $10 \%$. A non-tilting train with top speed $275 \mathrm{~km} / \mathrm{h}$ will also have longer running time than a tilting train with top speed of only $200 \mathrm{~km} / \mathrm{h}$.

\section{References}

[1] UIC. First report on tilting train technology. State of the art,UIC Paris, High speed division, 1998.

[2] UIC. Second report on tilting train technology. State of the art, working draft. UIC Paris, High-speed division, 2005. 
[3] R. Persson. a description and analysis of the present situation, KTH Stockholm, 2007,ISBN 978-917178-608-1.

[4] W. Deischl, Linienverbesserungen oder gesteuerteAchsen? VerkehrstechnischeWoche 31(1) (1937), pp. $97-108$.

[5] W. Van Dorn and P. Beemer, Suspension for vehicles, US Patent 2.225.242, 1938.

[6] Anon., Tilting Train. Available at http://en.wikipedia.org/wiki/Tilting train, history.

[7] Anon., Talgo. Available at http://en.wikipedia.org/wiki/Talgo, technology.

[8] D. Boocock and B.L. King, Development of the prototype Advanced Passenger Train, Proc. IMechE 196 (1982), pp. 35-46.

[9] H. Higaki, S. Fugimori, Y. Horike, T. Yasui, S. Koyanagi, I. Okamoto, and K. Terada, Active pneumatic tilting system for railway cars, Proceedings of 12th IAVSD Symposium, Vehicle Syst. Dyn. 20(Suppl.) (1991), pp. 254-268

[10] M. Dusing,Y. Lu, and J. Jakob, Wanksttze fr Schienenfahrzeuge, German Patent DE4311521C1, April 1994.

[11] A. Suescun, L.M. Martin, J.G. Gimenez, and J. Vinolas, Use of inverse dynamics in the development of tilt control strategies for rail vehicles, Vehicle Syst. Dyn. 25(Suppl.) (1996), pp. 655-667.

[12] H. Zamzuri, A.C. Zolotas, and R.M. Goodall, Intelligent control approaches for tilting railway vehicles, Proceedings of the 19th IAVSD Symposium, Vehicle Syst. Dyn. 44 (Suppl.) (2006), pp. 834-842.

[13] R.M. Goodall, A.C. Zolotas, and J. Evans, Assessment of the performance of tilt system controllers, Proceedings of the Railway Technology Conference, C580/028/2000, IMechE, Birmingham, UK, November 2000, pp. 231-239.

[14] K.W. Pennington and M.G. Pollard, The development of an electro-mechanical tilt system for the Advanced Passenger Train. IMechE Conference on Electric Versus Hydraulic Drives, Paper C299/83, 1983, pp. 21-28.

[15] R. Ford, SIG blows away the mystique of tilt, Railway Gazette Int. June, (1995), pp. 367-368.

[16] B. Sauer, The BR 611DMUwith new tilting technology, Proceedings of the International Conference on Railtech 96, IMechE Paper C511/8/076/96, 1996.

[17] Jenoptik, ESW Presentation. Available at http://www.epicos.com/WARoot/News/ESW_presentation.pdf, p. 27.

[18] G. Hauser, West coast main line trains, tilt technology, The Railway Technology Conference (RailTex), Birmingham, November 2002.

[19] G. Hauser, Alstom's Tiltronix anticipative tilt control, Le Rail, No 129, September 2006.

[20] Talgo, Talgo XXI. Available at http://www.talgo.es/pdf/T21ingles.pdf, p. 3.

[21] M. Griffin, Discomfort from feeling vehicle vibration, Vehicle Syst. Dyn. 45(7-8) (2007), pp. 679-698.

22] ISO, Mechanical vibration and shock - Evaluation of human exposure to whole body vibrations - Part 1: General requirements. ISO 2631-1.2 ISO, Geneva, 1997.

[23] CEN, Railway applications - Ride comfort for passengers - Measurements and evaluation, Enquiry Version prEN12299, CEN, Brussels, 2007.

[24] H. Suzuki, H. Shiroto, A. Tanka, K. Tezuka, and H. Takai, Psychophysical evaluation of railway vibrational discomfort on curved sections, Q. Rep. RTRI 41 (2000), pp. 106-111.

[25] I. Kaplan, Motion sickness on railroads, Ind. Med. Surg. 33 (1964), pp. 648-651.

[26] H. Suzuki, H. Shiroto, and K. Tezuka. Effect of low frequency vibration on train motion sickness, Q Rep. RTRI. 46 (2005), pp. 35-39.

[27] M. Ueno, T. Ogawa, S. Nakagiri, T. Arisawa,Y.Mino, K. Oyama, R.Kodera, T. Taniguchi, S. Kanazawa, T. Ohta, and H.Aoyama, Studies on motion sickness caused by high curve speed railway vehicles, Japanese J. Ind. Health 28 (1986), pp. 266-274.

[28] J. Förstberg, Motion-related comfort levels in trains:A study on human response to different tilt control strategies for high-speed trains, Licentiate Thesis KTH TRITA-FKT Report 1996:41 (also published as VTI Särtryc 274-1997 VTI. Linköing).

[29] M. Hughes, Tilt nausea is bad business, Railway Gazette Int. 153(4) (1997), p. 249.

[30] P.E. Gautier, Review of relations between track parameters, running safety and passenger comfort. In Proceedings from of UIC Conference Can Your Railway Benefit from Tilting Train Technology? UIC, Paris, 1999.

[31] J. Förstberg, Ride comfort and motion sickness in tilting trains: Human responses to motion environments in train and simulator experiments, KTH TRITA-FKT Report 2000:28 (also published as VTI Särtryc 336-2001 VTI. Linköing).

[32] C.A. Claremont, The psychology of sea sickness, Psyche 11 (1931), pp. 86-90.

[33] J. Reason and J. Brand, Motion Sickness, Academic Press, London, 1975.

[34] A.J. Benson, Motion Sickness. Aviation Medicine, 2nd ed., Butterworths, London, pp. 318-338, 1988.

[35] W. Bles, J.E. Bos, and H. Kruit, Motion sickness, Curr. Opin. Neurol. Neurosurg. 13 (2000), pp. 192

[36] W. Bles, J.E. Bos, B. de Graaf, E. Groen, and A.H.Wertheim, Motion sickness: Only one provocative conflict? Brain Res. Bull. 47(5) (1998), pp. 481-487.

[37] J.F. O'Hanlon and M.E. McCauley, Motion sickness incidence as a function of the frequency and acceleration of vertical sinusoidal motion, Technical Report 1733-1, Human Factors Research, Inc., Goleta, USA, 1973.

[38] B. Donohew and M. Griffin, Motion sickness: Effect of the frequency of lateral oscillation, Aviat. Space Environ. Med. 75(8) (2004), pp. 649-656.

[39] B. Kufver and J. Förstberg, A net dose model for development of nausea. Paper Presented at 34th Meeting of the UK Group on Human Response to Vibration 22-24 September 1999, Dunton, Essex, England (also published as VTI Särtryc 330-1999 VTI. Linköing).

[40] R. Persson, Motion Sickness in Tilting Trains, Description and Analysis of the Present Knowledge , ISBN 978- 91-7178-680-3, KTH, Stockholm, 2008.

[41] A. Prud'homme, La Résistance de la Voie aux Efforts Transversaux éxercés par le Material Roulant, Revue Generale des Chemin de Fer, 86-A, Paris, 1967, pp. 13.

[42] E. Andersson and L. Halling, Running gear for tilting trains, UIC/UNIFE/ERRI Interactive Seminar 
CanYour Railway Benefit from Tilting Train Technology, Paris, 6-7 May 1999.

[43] AEIF, Trans-European high-speed rail system, Technical Specification for Interoperability (TSI), Rolling Stock, Working Draft, 2006.

[44] AEIF, Trans-European high-speed rail system, Technical Specification for Interoperability (TSI), Infrastructure, 2002.

[45] B. Diedrichs, M. Ekequist, S. Stichel, and H. Tengstrand, Quasi-static modeling of wheelCrail reactions due to crosswind effects for various types of high-speed rolling stock, Proceedings of Institute of Mechanical Engineers, Vol. 218, Part F: Rail Rapid Transit, London, 2004.

[46] CEN, Railway applications $C$ Track alignment design parameters $C$ Track gauges $1435 \mathrm{~mm}$ and wider C Part 1: Plain line, Enquiry Version prEN13803-1, CEN, Brussels, 2007.

[47] B. Kufver. Tracks for tilting trains. European Commission Competitive and Sustainable Growth Programme C Fast and Comfortable Trains (FACT), Report D8, UIC, Paris, 2005. 